\title{
Tamarix Articulata Exhibits Antiproliferative and Antimetastatic Activity by Modulating PI3K-Akt and TGF- $\beta$-Mediated Downstream Signaling in Prostate Cancer Cells
}

\section{Abdullah M Alnuqaydan}

Qassim University College of Applied Medical Science

Abdulmajeed G Almutary

Qassim University College of Applied Medical Science

Abdullah M Alajlan

SFDA: Saudi Food and Drug Authority

Abdullah Al Tamim

Saudi Food and Drug Authority

Abdullah Alowaifeer

Saudi Food and Drug Authority

Mohd Younus Rather

Government Medical College Srinagar

Bilal Rah ( $\sim$ b.rah@qu.edu.sa )

Qassim University College of Applied Medical Science https://orcid.org/0000-0003-3673-5044

\section{Research Article}

Keywords: Tamarix articulata, plant extracts, metastasis, anticancer, prostate cancer, apoptosis, cell motility, cell invasion

Posted Date: February 24th, 2021

DOl: https://doi.org/10.21203/rs.3.rs-231626/v1

License: (c) (1) This work is licensed under a Creative Commons Attribution 4.0 International License. Read Full License 


\section{Abstract}

Anticancer drugs mainly kill tumor cells through the apoptosis mechanism, but they can become ineffective when tumor cells are metastatic. Thus, searching for plant-based extracts/compounds to curtail metastasis is extremely important. This study aims to evaluate the anticancer potential of Tamarix articulata (TA) extract against prostate cancer cells. MTT, Brd U, and trypan blue assays was performed to evaluate the cell viability. TUNEL assay were performed to determine apoptotic cells. Clonogenic, wound healing and Boyden chamber assay were conducted to evaluate the anti-clonogenic, anti-motility, and anti-invasive potential of TA. Zymography and immunoblotting were done to check the activity and expression of metalloproteases and proteins associated with metastasis. Our results demonstrated that

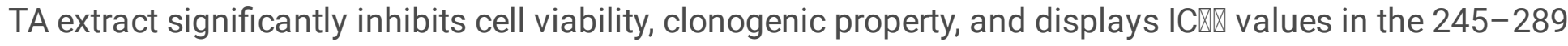
$\mu \mathrm{g} / \mathrm{mL}$ range. TA extract significantly abrogates the motility and invasive property of LnCaP cells in a dose-dependent manner. Mechanistically, TA extract downregulates the expression of PI3K-Akt/TGF- $\beta$ SMAD2/3 and MMP-2/-9 with concomitant upregulation of TIMP1 expression in LnCaP cells. Additionally, we observe a dose-dependent downregulation of snail and vimentin with the upregulation of E-cadherin protein expression in LnCaP cells. In conclusions, TA extract exhibits an antiproliferative effect, abrogates cell motility and invasion by downregulating PI3K-Akt/TGF- $\beta$-SMAD2/3, MMP-2/9, snail, and vimentin with concomitant upregulation of E-cadherin and TIMP1 expression in prostate cancer cells.

\section{Introduction}

Tumor metastasis is a series of events governed by complex mechanisms that are initiated by the detachment of tumor cells, followed by invasion, migration, endothelial cell adhesion, and finally reestablishment of tumor growth at distant sites [1]. Most tumor cells undergo apoptosis by chemotherapeutic drugs [2]. Some cells sustain chemotherapeutic drugs and often evade cell death mechanisms due to the accumulation of oncogenic mutations which enhance tumor cell growth [2]. These resistant cells can successfully advance metastatic dissemination to distant sites and pose a serious challenge to the current chemotherapeutics regimen [3]. Despite significant advances being made in the conventional therapeutics of cancer, tumor metastasis is still a major problem $[3,4]$. Owing to the absence of any therapeutics against metastasis, most cancer-related deaths occur due to metastasis [5]. One of the leading metastasis-associated deaths in Western countries, approximately $50 \%$ of prostate cancer patients clinically present with bone metastasis [6]. The therapeutic interventions for prostate cancer are surgery (radical prostatectomy), radiotherapy, and adjuvant chemotherapy [7]. The boneassociated metastasis in prostate cancer is extremely resistant to radiotherapy and to the present regiment of ablation of androgen therapy [7]. Owing to the development of androgen-independent prostate cancer, relapse is inevitable approximately after 18 months in prostate cancer metastasis. This indicates there is no therapeutic option for metastatic prostate cancer patients thereafter [8]. For this reason, new therapeutics are urgently required to treat metastatic prostate cancer.

Various cancers, including prostate cancer, are less evident in the Arab population compared to Western societies [9]. This may be due to the difference in prostate cancer screening, poor counseling for prostate- 
specific antigen (PSA) [10], low androgenic factors with high polyunsaturated fats in Mediterranean foods, which maintains the testosterone level under a certain level [11], and dietary advantages of plants having a great medicinal value [12].

Ever since ancient times plants have been used to treat numerous ailments [13]. Owing to the presence of secondary metabolites such as alkaloids, phenolics, and terpenoids, which act as defense mechanisms against both abiotic and biotic stresses, these compounds have promising medicinal importance [14]. One such plant in the deserts of Saudi Arabia containing a wide variety of secondary metabolites is TA [15]. This plant belongs to the family Tamaricaceae and is a halophytic plant growing in extremely harsh and arid conditions in the deserts of Saudi Arabia [16]. Commonly called Athal in the Arabic language, TA has been extensively used as a folk medicine by the Tafilalet, a tribal people in the south-eastern area of Morocco. The plant is woody and possesses great medicinal value. Traditionally, the plant is used to treat various ailments such as gastrointestinal diseases, skin diseases, heart diseases, and other ailments [16]. The phytochemical analysis of the methanolic extract of TA by LC-MS analysis reveals the identification of more than 200 compounds (Supplementary Table 1). The major compounds are encapsulated in Table 1 and their respective chromatogram were presented in Supplementary Fig. 1. The key phytochemicals identified from the methanolic extract of TA by LC-MS exhibits anticancer activities against various cellular models are summarized in Table 1. Additionally, the antiproliferative and antimetastatic activities of the TA extract are probably due to the synergistic interaction of major phytochemicals in the TA extract. Crude extracts of the plant have been reported to exhibit anticancer properties by inhibiting cell viability in various types of cancer cells in other parts of the world [17]. Consistent with the preliminary reports, our group also revealed that the methanolic extract of TA demonstrates promising antiproliferative activity against breast and colorectal cancer cells [18]. However, no data is yet available for the antimetastatic activity of TA extract. Subsequently, the current study evaluates the antiproliferative and antimetastatic activity of TA extract against prostate cancer cells. Our results demonstrate that TA extract significantly inhibits prostate cancer cell viability as well as the clonogenic property of prostate cancer cells. Further, we observe attenuation of cell migration and invasion property in LnCaP cells when exposed to varying doses of TA extract. The mechanistic studies revealed that TA extract downregulates the expression of PI3K-Akt/TGF- $\beta$-SMAD2/3 and their downstream target proteins MMP-2/-9 with concomitant upregulation of TIMP1 expression in LnCaP cells. Additionally, we observed reduced expression of mesenchymal-epithelial transition (MET)associated proteins snail and vimentin with a significant increase in the expression of E-cadherin protein when LnCaP cells were subjected to varying doses of TA extract for $24 \mathrm{~h}$. 
Table 1

Major constituents of Tamarix articulata which exhibits antitumor activity.

$\begin{array}{llll}\text { S. Major } & \text { Functions References } \\ \text { No } & \text { Constituents } & & \end{array}$

1. Solenopsin Exhibits antiproliferative activity and inhibits PI3K/Akt driven angiogenesis

2. Ailanthone Promotes apoptosis and autophagy by increases the expression of miR-195 in leukemia cells

[20]

Exhibits promising antiproliferative, and induces ROS-mediated

mitochondria-dependent apoptosis in breast cancer cells

4. Dronabinol Promotes antiproliferative activity and induces apoptosis by cannabinoid receptor (CB) $1 / 2$ in leukaemia cells

5. Oxymatrine Induces apoptotic cell death and arrests $\mathrm{GO} / \mathrm{G} 1$ cell cycle phase by blocks EGFR/PI3K/Akt/mTOR signaling in glioma cells

Immuno-modulatory effect, anticancer, anti-inflammatory, and antiviral activity

7. Resveratrol Exhibits antioxidant, anti-inflammatory and antiproliferative activity, interferes in many signaling pathways and activates apoptosis in cancer cell models

8. Rottlerin Antihypertensive, antiallergic and antifertility activities. Promotes

[26] antiproliferative activity by downregulates NF-kB and cyclin D1 expression.

\section{Materials And Methods}

\section{Collection of Plant Material and Preparation of Extract}

The plant material TA is scientifically well characterized belongs to clade: angiosperms, order: Caryophyllales, family: Tamaricaceae, genus: Tamarix and species: Tamarix articulata was collected in August 2019 from the deserts of Qassim province in the Kingdom of Saudi Arabia. A methanolic extract derived from the dry leaves was prepared as per the standard protocol published in our previous work [18]. After collection, the TA parts were first air-dried in the shade to remove the moisture completely. Using sharp blades, TA were chopped into small pieces, followed by grinding in a kitchen blender to produce a fine powder. After weighing $12 \mathrm{~g}$ of TA powder was added to $300 \mathrm{~mL}$ of $100 \%$ methanol and stirred constantly with magnetic bead for 5 days at room temperature. The mixture obtained was first filtered through a cheesecloth to remove the bulk followed by filtration through a Whatman filter paper in an autoclaved glass beaker. The methanol (solvent) was completely evaporated from the plant extract mixture in a glass beaker by keeping the temperature of the hot plate at $45^{\circ} \mathrm{C}$ to avoid the degradation of heat labile compounds. After the complete evaporation of solvent, the fine powder of residue was left in the glass beaker are collected and stored at $4^{\circ} \mathrm{C}$ in stored vials for future experiments to evaluate the biological activities of the TA. 


\section{Sample preparation}

Plant metabolites from TA were extracted as decried by previously published work [18]. Briefly, $50 \mathrm{mg}$ of plant material was weighed into an Eppendorf tube and $1 \mathrm{ml}$ of methanol was added, vortexed for $30 \mathrm{~s}$, then centrifuged for $15 \mathrm{~min}$ at $5000 \mathrm{rpm}$. After centrifugation, $200 \mu \mathrm{L}$ of the supernatant was diluted 5 folds with HPLC grade acetonitrile, and then filtered through a $0.2 \mu \mathrm{m}$ filter. Afterwards, the metabolic filtrate was transferred into an LC vial for analysis.

\section{LC-MS metabolomic analysis and data processing}

The analysis was carried out on an LC-MS consisted of an ACQUITY UPLC I-Class System (Waters Technologies, USA) coupled to a 6500 Qtrap (AB Sciex, Canada). The chromatographic separation was performed on a Zorbax XDB C18 column $(2.1 \times 150 \mathrm{~mm}$. $3.5 \mu \mathrm{m})$ (Agilent, USA) kept at $40^{\circ} \mathrm{C}$ with a flow rate of $300 \mu \mathrm{L} / \mathrm{min}$. The mobile phase consisted of $A(0.1 \%$ formic acid in HPLC grade water) and $B(0.1 \%$ formic acid in HPLC grade acetonitrile). The linear gradient elution was as follows: $2 \% B$ (from 0 to 2 ), 95\% B (from 2 to 24), 95\% B (held for $2 \mathrm{~min}$ ), then 4 min equilibration time. Electrospray ionization mass spectra (ESI-MS) was acquired in the positive (ES +), with an electrode voltage of $5500 \mathrm{~V}$. The declustering potential was set at $90 \mathrm{~V}$ and the entrance potential was $10 \mathrm{~V}$. Nitrogen was used as curtain gas (30 psi) and nebulizer gas on the MS. Spectra were collected with a mass range of $100-900 \mathrm{~m} / \mathrm{z}$. Data files from the LC were converted to MZxml format using MS Convert (ProteoWizard 3.0.20270). Analysis of the data was conducted using Mzmine software (version 2.53). After importing the data into MZmine, a minimum intensity cutoff of 1,000 was applied and the retention time was adjusted with a tolerance of $0.2 \mathrm{~min}$. Adjusted peaks were then aligned into one mass list to facilitate identification and comparison. The KEGG Database was used to identify compounds of interest in the finalized list based on $\mathrm{m} / \mathrm{z}$ with a tolerance of $30 \mathrm{ppm}$.

\section{Culturing of Cells and Treatments}

The cellular models of prostate cancer cells (PC-3, LnCaP, DU 145, C42B, and VCaP) along with benign hyperplasia normal (BPH) cells were ordered and purchased from the American Type Culture Collection (ATCC). All the purchased cell lines were cultured in their respective cell culture media [Roswell Park Memorial Institute (RPMI)-1640 (\#11875101) and Minimal Essential Medium (MEM, \#31095029)] in a 5\% $\mathrm{CO}_{2}$ incubator. The cell culture medium procured from Thermofisher Scientific, was supplemented with LGlutamine, and phenol red. Externally, culture media were added with $1 \%$ penicillin-streptomycin (penstrip, \#15140122), and 10\% fetal bovine serum (FBS, \#16000044) procured from Thermofisher Scientific. All the cell lines obtained from ATCC were regularly checked for all Mycoplasma contaminations.

\section{Chemicals, Reagents, and Antibodies}

Dimethyl sulphoxide (DMSO, \#D2650), phenylmethylsulphonyl fluoride (PMSF, \#52332), Propidium iodide (PI, \#4170), 3-(4, 5-dimethylthiazol-2-yl)-2, 5-diphenyltetrazolium bromide (MTT, \#M5655), triton X-100 (\#T8787), paraformaldehyde (\#158127), 4',6-Diamidino-2-phenylindole dihydrochloride (DAPI, \#D8417) and trypan blue (\#T6146) were ordered and purchased from Sigma Aldrich. However, primary antibodies 
were ordered and bought from cell signaling technology, these being $\beta$-actin (\#4970), PI3K-p110a (\#4249S), Akt (\#4691S), p-Akt-Ser473 (\#4060), TGF- $\beta$ (\#3711S), SMAD2 (\#5339S), SMAD3 (\#9523S), TIMP1 (\#8946S), MMP-2 (\#40994S), E-cadherin (\#14472S), Snail (\#3879S), Vimentin (\#5741S), and MMP-9 (\#13667S). From Santacruz Biotechnology, secondary antibodies, namely anti-rabbit IgG (SC2359) and anti-mouse IgG (SC-2005)-coupled with enzyme horseradish peroxidase (HRP) were procured.

\section{Preparation of TA Stock Solution}

The TA stock solution in DMSO $(10 \mathrm{mg} / \mathrm{ml})$ was prepared, aliquoted, and stored in autoclaved microcentrifuge tubes $(1.5 \mathrm{ml})$ at $-20^{\circ} \mathrm{C}$. At the time of the experiment stock concentration was diluted with culture media to prepare a working concentration $(10-10000 \mu \mathrm{g} / \mathrm{mL}(10-10000 \mu \mathrm{g} / \mathrm{mL}$ for exposing prostate cancer cells to varying doses of TA extract.

\section{Cell Proliferation Assay/Cell Cytotoxicity Assay}

The proliferation of prostate cancer cells was determined by the most used MTT assay [27]. Briefly, a panel of prostate cancer and transformed cells (PC-3, LnCaP, DU 145, and BPH) were subjected to harvesting and seeded at a density of $2 \times 10^{3}$ cells in each well of a 96-well plate. The seeded cells were exposed to various doses of TA extract $(10-10000 \mu \mathrm{g} / \mathrm{mL})$ along with DMSO control. After incubation lasting $24 \mathrm{~h}$ in a $5 \% \mathrm{CO}_{2}$ incubator, cells were flooded with $20 \mu \mathrm{l}$ of $2.5 \mathrm{mg} / \mathrm{mL}$ MTT dye and incubated for $3-4 \mathrm{~h}$ in a $5 \% \mathrm{CO}_{2}$ incubator at $37^{\circ} \mathrm{C}$. After incubation, it is necessary to remove the media containing MTT dye and add DMSO to dissolve formazan crystals. These were formed when cells were incubated in MTT dye. The purple-colored solution obtained after proper mixing or gentle shaking of the 96 -well plate was measured at $570 \mathrm{~nm}$ to record absorbance. The number of viable cells was analyzed as a percentage cell proliferation of treated cells compared to the untreated DMSO control group.

\section{Colony Formation Assay}

LnCaP cells $1 \times 10^{3}$ plated in the 6-well plates were treated with varying concentrations of TA extract (67.5, $125,250$, and $500 \mu \mathrm{g} / \mathrm{mL}$ ) along with control DMSO and staurosporine ( $25 \mathrm{nM})$ [28]. The treated cells were incubated in $5 \% \mathrm{CO}_{2}$ at $37^{\circ} \mathrm{C}$ for 5 days. Next, the medium was discarded, and the treated cells were washed with pre-cooled PBS. Following this the cells were fixed in ice-cooled methanol for $20 \mathrm{~min}$ and then stained with $0.5 \%$ crystal violet solution for about $15 \mathrm{~min}$. The cellular colonies stained in each well of the 6-well plate were photographed with a phase-contrast microscope, and the cells in each colony were counted.

\section{Scratch Motility (Wound Healing) Assay}

Briefly, prostate cancer cells (LnCaP) were harvested from the culture flask followed by seeding of $5.5 \times 10^{5}$ cells in each well of the 6-well plate [29]. After overnight incubation in a $5 \% \mathrm{CO}_{2}$ incubator at $37^{\circ} \mathrm{C}$, a complete matt of the monolayer was formed of the cells. In the middle of each well, a scratch was made with a sterile $200 \mathrm{ul} \mathrm{microtip} \mathrm{to} \mathrm{create} \mathrm{a} \mathrm{wound.} \mathrm{The} \mathrm{6-well} \mathrm{plate} \mathrm{with} \mathrm{serum-free} \mathrm{media} \mathrm{was}$ employed to wash out detached cells while creating a wound. After clearing detached cells, wound- 
created wells were exposed to varying concentrations of TA extract, i.e., $67.5,125,250$, and $500 \mu \mathrm{g} / \mathrm{mL}$ in the presence of untreated control and positive control camptothecin $2 \mu \mathrm{M}$ for $24 \mathrm{~h}$. Next, the cells were analyzed under a microscope, and then photographs were taken of areas where the wound was created at $0 \mathrm{~h}$. The percentage of wound closure was measured by using the formula as follows:

$\%$ age of wound closure $=$ [1-(area of wounding after $24 \mathrm{~h} /$ area of the wound at $0 \mathrm{~h}$ ) $\times 100 \%$ ]

\section{Transwell Boyden Chamber Invasion Assay}

Briefly, $1.25 \times 10^{6} \mathrm{LnCaP}$ cells were harvested, counted, and added uniformly to the culture medium without serum in upper insert of the Transwell Boyden chamber plate and subsequently subjected to varying doses of TA extract $(67.5,125,250$, and $500 \mu \mathrm{g} / \mathrm{mL})$. This occurs in the presence of control (untreated) and camptothecin $2 \mu \mathrm{M}$ as a positive control. The lower chamber was filled with $10 \%$ serumcontaining media as the chemoattractant. Re-suspended cells exposed to varying concentrations of TA extract tried to move towards the lower chamber containing $10 \%$ serum media. After $24 \mathrm{~h}$, the porous Matrigel-coated polycarbonate insert membrane was removed and the attached cell inside the insert was completely wiped off with a swab of cotton. These cells adhered to the bottom outside of the upper insert were fixed in pre-cooled methanol for $15 \mathrm{~min}$. This was followed by staining the cells with $0.25 \%$ crystal violet solution in PBS. Then this stained porous biological membrane was put under a microscope to examine cells and subsequently photographed. The cells which can cross the membrane were photographed and counted under a phase-contrast microscope.

\section{Gelatin Zymography}

Prostate $(\mathrm{LnCaP})$ cancer $5 \times 10^{5}$ cells were harvested and plated in a 6 -well plate as performed previously [27]. Cells were exposed to varying concentrations of TA extract $(67.5,125,250$, and $500 \mu \mathrm{g} / \mathrm{mL})$ along with control DMSO and camptothecin $(2 \mu \mathrm{M})$ as a positive control for $24 \mathrm{~h}$. The conditional medium obtained from each treated well along with untreated control and positive control were collected in separate autoclaved $2 \mathrm{ml}$ microcentrifuge tubes. Each sample was subjected to protein estimation by the standard Bradford method. The equal protein concentration of all samples was mixed with loading dye. The samples were loaded in the wells of SDS-PAGE gel containing $0.1 \%$ gelatin and the gel could resolve by setting the voltage initially at $80 \mathrm{~V}$ and after samples entering the resolving gel set the voltage at $100 \mathrm{~V}$ for $3 \mathrm{~h}$ at $4^{\circ} \mathrm{C}$. The resolved gelatin gel was washed with a $2 \%$ Triton X-100 buffer to remove SDS. The gel with incubation buffer was incubated to renature the matrix metalloproteinases for $24 \mathrm{~h}$ at $37^{\circ} \mathrm{C}$. Following this, the gel with Coomassie brilliant blue solution was stained for 1 to $2 \mathrm{~h}$, followed by distaining of gel with a mild destaining solution to ensure clear bands appeared. The gelatinase activity was determined by analyzing clear transparent bands against the dark blue background after Coomassie brilliant blue staining.

\section{Immunoblotting}

Briefly, $50 \times 10^{5}$ cells $(\mathrm{LnCaP})$ were plated in each well of the 6-well plate and they were allowed to adhere overnight to the bottom surface of the well in a $5 \% \mathrm{CO}_{2}$ incubator at $37^{\circ} \mathrm{C}$. The attached $\mathrm{LnCaP}$ cells were 
exposed to varying doses of TA extract $(67.5,125,250$, and $500 \mu \mathrm{g} / \mathrm{mL})$ along with DMSO vehicle [30]. After $24 \mathrm{~h}$, the treated cells were gently washed with pre-cooled PBS, scraped, and harvested the cells in a sterile microcentrifuge tube. $500 \mu \mathrm{l}$ of lysis buffer which contained PMSF and protease cocktail inhibitor were added, and cells repeatedly agitated intermittently for 10 seconds and kept on ice for 2-3 min. This was done 5 times to ensure complete lysis. The cell lysate solution was centrifuged at a speed of 12000 $\mathrm{g}$ for $15 \mathrm{~min}$ at $4^{\circ} \mathrm{C}$ to collect the supernatant. Using the Bradford method, the collected supernatant was subjected to the process of estimating protein concentration. 15-20 $\mu$ g protein from each TA exposed cell sample was calculated for loading in SDS-PAGE gel and resolving the gel. This followed the protocol mentioned in the above reference. Then SDS-PAGE gel was transferred onto the PVDF membrane followed by incubation of this membrane in a blocking solution containing $5 \%$ fat-free milk. This served to block nonspecific sites. The PVDF membrane was incubated with primary antibody solution for 3-4 $\mathrm{h}$ at room temperature or overnight at $4^{\circ} \mathrm{C}$. Subsequently, the PVDF membrane was washed with TBST 6 times followed by incubation with secondary antibody labeled with enzyme horseradish peroxidase for 1 h 30 min at room temperature. After incubation was completed the PVDF membrane was washed with TBST 6 times and each washing lasted 5 min. After washing, cleaning, and drying the PVDF membrane, immunoreactive substance enhanced the process of chemiluminescence to detect the bands on the PVDF membrane. The chemiluminescent signal on the PVDF membrane with the $x$-ray films was captured after proper exposure under dark conditions or with inbuilt chemiluminescent gel doc.

\section{Cell Proliferation (brd U) Assay}

Antiproliferative activity of TA extract against a panel of prostate cancer cell lines was evaluated by using colorimetric method Brd U cell proliferation ELISA kit (Abcam \#Ab126556). Briefly, $2 \times 10^{3}$ cells were plated in each well of 96 -well plate overnight. After adhered properly to the bottom surface of well, cells were exposed to varying doses $(10-10000 \mu \mathrm{g} / \mathrm{mL})$ of TA extract for $24 \mathrm{~h}$ at $37^{\circ} \mathrm{C}$ in $5 \% \mathrm{CO}_{2}$ incubator in triplicates. After the exposure of cells with TA extract, as per the manufacturer's instruction, cells were incubated with Brd $\mathrm{U}$ for $2 \mathrm{~h}$ at $37^{\circ} \mathrm{C}$ to incorporate Brd $\mathrm{U}$ in DNA. The cells were fixed, permeabilized and desaturated, followed by gentle washing and aspiration. Cells were incubated with anti-Brd U monoclonal antibody for $1 \mathrm{~h}$, at room temperature. After proper incubation and removal of unbound fraction of antiBrd U from wells by gently washing and aspiration, wells were incubated with TMB solution containing enzyme-labeled goat antimouse antibody. After the formation of color by enzymatic reaction indicates the cell proliferation, the stop solution was added, and absorbance were recorded immediately by using multiplate reader.

\section{Cell Counting (trypan Blue) Assay}

Briefly $5 \times 10^{4}$ prostate cancer cells were plated in each well of 24-well plate. After properly adhered to the bottom surface, cells were exposed to dose-dependent $(10-10000 \mu \mathrm{g} / \mathrm{mL})$ treatment with TA extract for $24 \mathrm{~h}$ at $37{ }^{\circ} \mathrm{C}$ in $5 \% \mathrm{CO}_{2}$ incubator. After the completion of time point the treated cells were harvested and 
stained with trypan blue dye. The dead cells were stained with trypan blue; however, live cells were easily counted by trypan blue exclusion test.

\section{Phase-contrast Microscopy}

Phase-contrast microscopy was performed to detect the change in cellular morphology of prostate cancer cells after dose-dependent treatment with TA extract for $24 \mathrm{~h}$. Briefly, $0.5 \times 10^{6}$ were seeded per well of 6 well plate and exposed to different doses of TA extract for $24 \mathrm{~h}$. After the completion of treatment cells were analyzed by phase-contrast microscope inbuilt with camera to detect any change in cellular morphology of cells.

\section{Detection Of Apoptosis By Tunel Assay}

Detection of apoptotic population of prostate cancer cells after exposed to varying doses of TA extract for $24 \mathrm{~h}$ were detected by TUNEL (Terminal Transferase dUTP Nick End Labeling) assay apoptosis detection kit (Roche). After seeding the LnCaP cells at a density of $5 \times 10^{5}$ per well on the sterile coverslips placed within the wells of 6-well plate were incubated overnight in $5 \% \mathrm{CO}_{2}$ at $37^{\circ} \mathrm{C}$. After the completion of exposure time $(24 \mathrm{~h})$ to various doses of TA extract $(67.5,125,250$, and $500 \mu \mathrm{g} / \mathrm{mL})$, cells grown on the coverslips were processed for fixation (4\% paraformaldehyde), permeabilization (4\% Triton $\mathrm{X}-100$ ) at room temperature for $10 \mathrm{~min}$. Next, cells grown on the coverslips were incubated with a mixture of terminal deoxynucleotidyl transferase (TdT) and biotin-dUTP for $1 \mathrm{~h}$, followed by 30 min incubation with avidin-FITC solution in dark. Subsequently, DAPI solution was added to stain the nucleus. After the completion of TUNEL staining, coverslips containing cells were put on to the clean grease-free glass slide and seal the edges with nail-polish to avoid any dry ness of the slide. The glass slides were analyzed by confocal microscope (Zeiss LSM 710 META, Germany) for the detection of TUNEL positive cells.

\section{Statistical Analysis}

All the experiments in the current study were performed at least three or more times. Statistical analysis of all the independent experiments was conducted by using GraphPad Prism software. The results obtained were expressed as \pm SEM. All the experiments were analyzed using one-way ANOVA. Statistical significance was expressed as $p$-value, wherein the $p$-value of less than or equal to 0.05 was significant.

\section{Results}

TA Extract Exhibits the Promising Antiproliferative Activity, Induces Apoptotsis and abrogates Clonogenic Property in Prostate Cancer Cells

Previous reports documented that numerous plant extracts exhibit an antiproliferative effect against a variety of tumor cell models [31,32]. Our preliminary published work also revealed the inhibition of tumor 
cells (breast and colorectal) by TA extract [18]. We also intended to examine the antiproliferative potential of TA extract on the cellular growth of prostate cancer (PC-3, DU 145, LnCaP, C42B, and VCaP) cells and normal benign prostate hyperplasia (BPH) cell line. The antiproliferative potential of TA extract was analyzed using the MTT assay to determine the percentage of cell viability. Our MTT results showed that TA extract can start inhibiting prostate cancer cell growth at a dose of $10 \mu \mathrm{g} / \mathrm{mL}$. Using GraphPad Prism to evaluate the $\mathrm{IC}_{50}$ value of TA extract against a panel of prostate tumor cells, we observed the $\mathrm{IC}_{50}$ values of TA extract are 245, 248, 256, 289, and $273 \mu \mathrm{g} / \mathrm{mL}$ against LnCaP, PC-3, DU 145, C42B, and VCaP cells, respectively (Fig. 1a). Intriguingly, we observe a significantly high $\mathrm{IC}_{50}$ value $(9541 \mu \mathrm{g} / \mathrm{mL})$ of normal benign prostate hyperplasia (BPH) cells when exposed to varying doses of TA extract. This indicates that TA extract attenuates prostate tumor cell growth specifically and exhibits a safe level of toxicity against normal transformed cells (BPH). To further confirm the antiproliferative potential of TA extract, we perform Brd $\mathrm{U}$ incorporation and trypan blue exclusion assays. Our results showed a significant reduction of Brd U incorporation (a thymidine analogue) $\left({ }^{\star} p<0.05,{ }^{\star *} p<0.01\right.$ ) (Fig. 1b) and viability of cells by trypan blue exclusion assay $\left({ }^{\star} p<0.05,{ }^{\star \star} p<0.01\right)$ (Fig. 1c) were observed after prostate cancer cells were exposed to varying doses of TA extract for $24 \mathrm{~h}$. Moreover, phase-contrast microscopy of LnCaP cells after dose-dependent treatment with TA extract $(67.5,125,250,500 \mu \mathrm{g} / \mathrm{mL})$ for $24 \mathrm{~h}$ reveals a prominent change in morphology of cells in treatment cells compared to untreated control. The alteration in morphology was maximum at the higher doses of TA extract treatment (Fig. 1d). Together, these findings demonstrate that TA extract has a promising antiproliferative effect that specifically promotes the death of prostate cancer cells. It is accompanied by less antiproliferative activity against normal benign prostate hyperplasia (BPH) cells.

We next intended to evaluate whether the TA extract induced antiproliferative effect in prostate cancer cells is due to apoptosis. To do so we perform TUNEL assay. After the dose-dependent exposure of LnCaP cells to TA extract $(67.5,125,250,500 \mu \mathrm{g} / \mathrm{mL})$ for $24 \mathrm{~h}$, cells in all treatments including untreated control were incubated with a mixture of TdT and biotin-dUTP, followed by avidin-FITC for $30 \mathrm{~min}$ and nuclear staining (DAPI) in the dark.

Our results showed that the number of TUNEL-positive cells increases as the treatment dose of TA extract increases (Fig. 2a). The maximum number of TUNEL-positive cells were observed $\left(32 \%,{ }^{\star} p<0.05\right)$ when exposed to $500 \mu \mathrm{g} / \mathrm{mL}$, followed by $\left(11 \%,{ }^{*} p<0.05\right)$ at $250 \mu \mathrm{g} / \mathrm{mL},(7 \%, * \star p<0.01)$ at $125 \mu \mathrm{g} / \mathrm{mL}$ and $(5 \%$, ${ }^{\star \star} p<0.01$ ) at $67.5 \mu \mathrm{g} / \mathrm{mL}$ dose of TA extract compared to untreated control (Fig. 2b). Collectively, these results suggest that TA extract induces cell death of prostate cancer cells by apoptosis mechanism and the effect is promising at higher doses of TA extract.

Additionally, we intended to evaluate whether the clonogenic property of prostate cancer cells was also attenuated using TA extract. Our results revealed that sub-toxic doses of TA extract treatment lasting 24 $h$, significantly reduce the ability of LnCaP cells to form colonies at higher doses of TA extract when compared to untreated control. Further, the anti-clonogenic effect of TA extract at a high concentration $(250 \mu \mathrm{g} / \mathrm{mL})$ was as good as that of positive control staurosporine $(25 \mathrm{nM})$ (Fig. 3a, b). It suggests that TA extract has potential for anti-colony formation and can fight against prostate ( $\mathrm{LnCaP}$ ) cancer cells. 


\section{TA Extract Abolishes Migration, Motility, and Invasive Property of Prostate Cancer Cells}

To evaluate whether, TA extract could also abrogate the motility, migration, and invasive property of prostate malignant cells under in vitro settings, we planned to execute the wound healing assay to examine the antimetastatic activity after exposing LnCaP cells to varying doses of TA extract. Owing to the high percentage of cell death at higher doses of TA, the subtoxic doses $(67.5,125,250 \mu \mathrm{g} / \mathrm{mL})$ of TA extract for $24 \mathrm{~h}$ were intelligently selected to nullify any biased antimetastatic effect at high dose (500 $\mu \mathrm{g} / \mathrm{mL}$ ) of TA extract when the antimotility evaluation was performed on LnCaP cells. Our wound healing results demonstrated a significant decline in cell migration and motility was observed when LnCaP cells were exposed to 125 and $250 \mu \mathrm{g} / \mathrm{mL}$ of TA extract (Fig. 4a, b) compared to untreated DMSO control which was almost filled with cells migrated from adjacent areas. Further, the anti-migration effect of 250 $\mu \mathrm{g} / \mathrm{mL}$ of TA extract was statistically significant when compared to positive control camptothecin $(2 \mu \mathrm{M})$, which indicates that the TA extract displays excellent anti-migration properties against prostate cancer cells.

The crucial step in metastasis is for the tumor cells to use a cascade of oncogenic mutations in order to invade or cross various physical barriers and spread to distant secondary sites [33,34]. To evaluate whether TA extract could have an inhibitory impact on the invasive property of prostate malignant cells, we perform the Transwell Boyden chamber assay to determine whether TA extract attenuates the prostate cancer cell migration through the porous Matrigel membrane of the upper insert of the Transwell Boyden chamber. We observe a substantial number of invasive cells fail to infiltrate via porous Matrigel membrane at higher doses of TA extract compared to untreated control (Fig. 5a). Additionally, our histogram analysis revealed that the number of invasive cells is 77,58 , and 28 at a dose of $67.5,125$, and $250 \mu \mathrm{g} / \mathrm{mL}$ of TA extract, respectively, when compared to 149 invasive prostate malignant cells in the untreated control (Fig. 5b). Further, the high dose $(250 \mu \mathrm{g} / \mathrm{mL})$ of TA extract attenuates invasion of prostate cancer ( $\mathrm{LnCaP}$ ) cells through the Matrigel membrane as effectively as that of positive control camptothecin $(2 \mu \mathrm{M})$. Together, these findings demonstrate that TA extract inhibits the cellular motility, migration, and invasion of prostate cancer cells significantly. Furthermore, and equally importantly, the antimetastatic activity of TA extract at high dose is as effective as that of positive control camptothecin. This is a well-known chemotherapeutic drug used in clinics to combat various types of malignancies.

\section{TA Abrogates Matrix Metalloproteins MMP-2/-9 Activity as well as Expression in Prostate Cancer Cells}

Metastasis is a cascade of a complex process which includes cell invasion, motility migration, and last but not the least the activation and upregulation of matrix metalloproteinases (MMPs). This functions to break the physical barrier in the form of the basement membrane and allow malignant cells to spread to distinct sites from the primary tumor site. Previous reports suggest that significantly high expression of MMPs has been implicated in metastasis $[35,36]$. As mentioned earlier and discussed above the anti- 
metastatic activity of TA extract against prostate malignant cells, we intended to evaluate whether TA extract could exhibit anti-MMPs activity secreted by LnCaP cells. We observe a prominent decrease in MMPs activity (MMP-2/-9) by zymography in the conditional media samples collected after exposure to varying doses of TA extract for $24 \mathrm{~h}$ (Fig. 6a, b). To evaluate whether TA extract downregulates the expression of MMPs at the translation level, we performed immunoblotting of LnCaP cells exposed to varying doses of TA extract for $24 \mathrm{~h}$. Our immunoblotting results also revealed there is a significant downregulation in the expression of MMP-2/-9 proteins at higher doses of TA extract compared with untreated control (Fig. 6c, d). Together, these findings suggest that larger doses of TA effectively abrogate activity as well as expression of MMP-2/-9 at the translational level which plays an important role in metastasis.

\section{TA Extract Exerts Antimetastatic Effect by Modulating PI3K-Akt/TGF- $\beta$ Pathways and Their Downstream Targets in Prostate Cancer Cells}

Previous reports suggest there is a strong correlation of deregulated PI3K-Akt signaling pathway activation due to frequent PTEN mutation in prostate cancer cells, and performs a vital role in cell migration, invasion as well as motility of malignant cells $[37,38]$. Therefore, we intended to explore whether TA extract could inhibit PI3K/Akt signaling in prostate cells. As displayed in Fig. 7a, b our Western blotting analysis of $\mathrm{LnCaP}$ cell lysates treated with varying doses $(67.5,125,250$, and 500 $\mu \mathrm{g} / \mathrm{mL}$ ) of TA extract inhibits phosphorylation of PI3K-P110a protein in a dose-dependent way. The PI3KAkt pathway and its downstream mediators play a critical role in transferring and augmenting extracellular signaling to intracellular adapter proteins in prostate malignant cells and modulate cellular processes in favor of tumor growth [39]. To evaluate whether the TA extract can also modulate the downstream mediators of PI3K-Akt signaling, our Western blotting results demonstrated a significant downregulation of phosphorylated p-Akt-Ser-473. This was evident when prostate malignant cells were exposed to higher doses of TA extract for $24 \mathrm{~h}$. Further, we did not observe any significant change in the expression of total Akt in the same samples. The TGF- $\beta$ signaling pathway plays a major role in epithelial-mesenchymal transition (EMT) and metastasis of prostate cancers cells [40]. To explore whether TA extract could also attenuate the TGF- $\beta$-mediated EMT associated metastasis in prostate cancer. We expose LnCaP cells to dose-dependent treatment of TA extract $(67.5,125,250$, and 500 $\mu \mathrm{g} / \mathrm{mL}$ ) for $24 \mathrm{~h}$. Our immunoblotting results revealed that the TA extract downregulates the expression of TGF- $\beta$ and its downstream mediators SMAD2 and SMAD3 in dose-dependent manner (Fig. 7c, d). Further, to investigate whether TA extract-mediated downregulation of PI3K-Akt and TGF- $\beta$-SMAD2/3 signaling pathways could have any impact on mesenchymal-epithelial proteins (MET), which are the key mediators in cell migration and invasion, we expose prostate malignant ( $\mathrm{LnCaP}$ ) cells to varying doses of TA extract $(67.5,125,250$, and $500 \mu \mathrm{g} / \mathrm{mL})$ for $24 \mathrm{~h}$. Through our immunoblotting experiments, we observe a prominent decline in the expression of MET proteins snail and vimentin with simultaneous induction in the protein expression of E-cadherin and TIMP1 at higher doses of TA extract (Fig. 7e, f). Together, these findings suggest that TA extract mitigates PI3K-Akt/ TGF- $\beta$-SMAD2/3 stimulation and subsequently does not transmit a signal downstream associated proteins snail and vimentin that are regulating tumor cell invasion in prostate cancer cells. 


\section{Discussion}

TA is a halophytic plant, growing in the extremely harsh environmental conditions. It exhibits promising biological activities such as antioxidant, antidiabetic, hypolipidemic, antibacterial, and hepatoprotective activities $[15,16,18,41-43]$. TA displayed anti-tumor activity by modulating miRNA-1275 which plays a crucial role in the development of tumorigenesis [17]. The current investigation discovered that TA extract promotes antiproliferative, anticlonogenic, antimigratory and anti-invasive activity against prostate malignant cells. Mechanistically, TA extract modulates PI3K-Akt and TGF- $\beta$-SMAD $2 / 3$ signaling in prostate cancer cells. Further TA extract downregulates its downstream signaling mediators MMP-2/-9 and MET-associated proteins snail, vimentin with concomitant upregulation of TIMP1, and E-cadherin. These observations revealed that TA extract can be the main source of promising anticancer agents to prevent prostate tumorigenesis in the future.

Numerous plants and derived products possess various phytochemicals that exhibit potential pharmacological properties such as anti-inflammatory, anti-diabetic and anti-cancer. Consequently, these plants and their derived products can act as a crucial source for drugs against various diseases including cancer with less deleterious effects on normal cells [44]. To date, approximately $50 \%$ of food and drug administration (FDA)-approved drugs are either directly extracted from plants or their products [45]. The in vitro cellular models and preclinical studies have revealed that a significant number of plant species have still not been evaluated for their phytochemical characteristics, even though they potentially exhibit promising pharmacological activity with great efficacy and fewer toxicity issues. TA is one such plant from Saudi Arabia which has not been evaluated completely for its pharmacological analysis. Although there are some reports that TA extract displays some pharmacological activities such as antiinflammatory, anti-oxidative, hepatoprotective, and antitumor activity in some tumor cell lines. For this reason, the current study aims to assess the anticancer activity and investigate the possible underlying inhibitory mechanism against prostate cancer cells. The phytochemical analysis of the methanolic extract of TA by LC-MS analysis reveals the identification of some major compounds (Supplementary Fig. 1, Table 1) which exhibit anticancer properties are summarized in Table 1.

Previous reports suggest that a mixture of phytochemicals in plant extracts exhibits a wide range of promising pharmacological activities due to the synergistic or additive effect of key phytochemicals in the extract. However, when these compounds were isolated individually for the evaluation of biological activity, these either lost the activity or were reduced significantly. Consistent with these findings, the antiproliferative and antimetastatic activities of the TA extract are probably due to the synergistic interaction of major phytochemicals with other compounds in the extract. Our initial experiments demonstrated that TA extract exhibits promising cytotoxic activity by significantly reducing the viability of prostate cancer cells. Intriguingly, we observed an incredibly low cytotoxic effect of TA extract at the same dose and time against normal benign prostate hyperplasia (BPH) cells. Furthermore, we found a $50 \%$ cell population of BPH cells were killed at a dose (ICQV $=9541 \mu \mathrm{g} / \mathrm{mL})$ by TA extract which is a significantly much higher dose. Additionally, the antiproliferative activity of TA extract against a panel of prostate cancer cells were also supported by Brd U incorporation, and trypan blue exclusion assays. The 
phase-contrast microscopy to analyze morphological changes further demonstrate the dose-dependent antiproliferative effect of TA extract. These results suggest that TA extract not only kills prostate cancer cells specifically with less dose requirement to kill $50 \%$ cell population; it also possesses insignificant cytotoxicity against normal prostate cells with a safe toxicity profile.

Buranrat et al. revealed that Oroxylum Indicum extracts displayed promising antiproliferative effects against breast adenocarcinoma cells by modulating the expression of Rac1 signaling. Furthermore, the study reveals that downregulation of Rac1 expression abrogates adenocarcinoma cell migration and abolishes both MMP-9 activity and protein expression in breast cancer cells [46]. A similar study by Parr et al. revealed that a significant attenuation of hepatocyte growth factor (HGF)-mediated cell invasion and migration of prostate cancer cells was observed in Boswellia frereana extract at higher doses. Furthermore, the analysis confirmed that Boswellia frereana extract-mediated abrogation of prostate cell migration and invasion was due to modulation of c-Met signaling [47]. Consistent with these previous studies, we observe TA extract displays a considerable decrease in the cell motility of prostate cancer cells. To address any rational discrimination of TA extract in controlling the migration property of tumor cells with apoptosis, we carefully chose the concentrations of TA extract that are not lethal to cells. TUNEL assay results suggest that $125 \mu \mathrm{g} / \mathrm{mL}$ of TA extract does not promote significant cell death (7\%), yet the same dose could modulate the migration of prostate cancer cells significantly to that of untreated control cells placed in a 6-well plate which was significantly occupied with migrated cells. The striking feature of metastasis is the ability to disseminate malignant cells to distant secondary sites by crossing various physical barriers such as the extracellular basement matrix [48]. Interestingly, our results support the view that sub-lethal concentrations of TA extract considerably impede several tumor cells that possess the ability to infiltrate a perforated Matrigel-coated membrane.

Accumulating evidence demonstrates that aberrant PI3K-Akt-mediated signaling plays a crucial role in tumor cell growth. Recent reports suggest that the PI3K-Akt pathway-mediated cell migration and invasion in various types of solid malignancies to distant sites occurred through various downstream mediators $[49,50]$. Moreover, recent reports suggest a strong correlation between the PI3K-Akt and associated signaling pathway with cancer cell migration, invasion, metastasis, and development of chemotherapeutic drug resistance [51, 52]. In our study, we observe that TA extract downregulates the phosphorylation of the PI3K-Akt signaling pathway in prostate cancer cells. The TGF- $\beta$ signaling pathway is well documented to play a critical role in tumorigenesis and metastasis [40]. Recent reports suggest that TGF- $\beta$ pathway regulates laminin, collagen, fibronectin, and MMP-9 thereby modulates invasive and migratory ability of tumor cells [53]. Accumulating evidence revealed that various herbal medicines such as anthocyanidins, thymoquinone and curcumin abrogates EMT and attenuates metastasis by downregulating TGF- $\beta$-SMAD2/3 signaling $[54,55]$. Consistent with previous findings, our results revealed a dose-dependent downregulation of TGF- $\beta$, SMAD2/3 expression upon treatment of LnCaP cells with TA extract for $24 \mathrm{~h}$. Interestingly, our results suggest that the higher doses of TA extract not only downregulate the phosphorylation status of PI3KA-kt or reduction in TGF- $\beta$, SMAD2/3 expression but also significantly abolish the expression of proteins which play a crucial role in tumor cell invasion, migration, and metastasis. Examples here include MMP-2/-9 and MET-associated proteins snail and vimentin. 
Additionally, exposure of prostate malignant cells to higher doses of TA extract upregulates the protein expression of TIMP1 and E-cadherin, which regulated migration and invasion of cells in a quite different way to that of MET proteins. Collectively, our results infer that the TA extract promotes antimetastatic activity which includes antimotility, anti-migration, and anti-invasion property against prostate malignant cells. It does this by attenuating the hyperactivation of aberrant PI3K/Akt signaling and its downstream targets which plays a critical role in tumor metastasis.

\section{Conclusion}

Our findings for the first time revealed that TA extract exhibits cytotoxic, anti-clonogenic, and antimetastatic properties against prostate cancer cells. Mechanistically, TA extract downregulates the expression of PI3K-Akt, TGF- $\beta$-SMAD2/3 and its downstream target proteins MMP-2, MMP-9, and METassociated proteins snail and vimentin which play an important role in invasion and migration during the metastasis process. Additionally, we observe the upregulation of tight junction protein expression Ecadherin and TIMP1 in prostate cancer cells when exposed at higher doses of TA extract. The schematic in Fig. 7 depicts the possible underlying mechanism of antitumor properties of TA extract against prostate cancer cells. In summary, we conclude that TA extract has promising anticancer properties that can fight prostate cancer cells. This should be evaluated in preclinical models in future studies to document its therapeutic potential against prostate cancer and other malignancies.

\section{Abbreviations}

TA

$\mathrm{PI} 3 \mathrm{~K}$

AKT

MMP

TIMP

MET

PSA

DMSO

PMSF

PI

MTT

\section{Tamarix articulata}

Phosphatidyl inositol 3-kinase

Protein kinase B

Matrix metalloproteinase

Tissue inhibitor of metalloproteinases

Mesenchymal-epithelial transition.

Prostate specific antigen

Dimethyl sulphoxide

Phenylmethylsulphonyl fluoride

Propidium iodide

3-(4,5-dimethylthiazol-2-yl)-2,5-diphenyltetrazolium bromide 
ATCC American Type Culture Collection

MEM Minimal Essential Medium

Pen-strep Penicillin-streptomycin

FBS Fetal bovine serum

HRP Horseradish peroxidase

SDS-PAGE Sodium dodecyl sulphate-polyacrylamide gel electrophoresis

\section{Declarations}

Acknowledgments The authors extend their appreciation to the Deputyship for Research \& Innovation, Ministry of Education in Saudi Arabia for partial funding this research work through post-doc project entitled "The potential of naturally derived plant compounds in Saudi Arabia such as Tamarix articulata to act as anticancer (antioxidant activity) to protect against liver cancer, stomach cancer, lung cancer or skin disease" with post doc project number QUPOST-DOC002.

Author Contributions Conceptualization, Bilal Rah, Abdulmajeed G Almutary and Abdullah Alnuqaydan; Data curation, Bilal Rah, Abdullah Alnuqaydan, Abdulmajeed G Almutary and Abdullah Alowaifeer; Formal analysis, Bilal Rah, Abdullah Alnuqaydan, Abdullah M Alajlan, Abdullah Al Tamim, Abdullah Alowaifeer and Mohd Younis Rather; Funding acquisition, Bilal Rah, Abdulmajeed G Almutary and Abdullah Alnuqaydan; Investigation, Bilal Rah and Abdullah Alnuqaydan; Methodology, Bilal Rah, Abdulmajeed G Almutary, Abdullah Alnuqaydan, Abdullah M Alajlan, Abdullah Al Tamim, Abdullah Alowaifeer and Mohd Younis Rather; Project administration, Bilal Rah and Abdullah Alnuqaydan; Resources, Bilal Rah, Abdullah Alnuqaydan, Abdullah M Alajlan, Abdullah Al Tamim, Abdullah Alowaifeer and Mohd Younis Rather; Software, Bilal Rah, Abdulmajeed G Almutary, Abdullah Alnuqaydan, Abdullah M Alajlan, Abdullah Al Tamim, Abdullah Alowaifeer and Mohd Younis Rather; Supervision, Bilal Rah and Abdullah Alnuqaydan; Validation, Bilal Rah, Abdullah Alnuqaydan, Abdullah M Alajlan, Abdullah Al Tamim and Mohd Younis Rather; Visualization, Bilal Rah, Abdullah Alnuqaydan and Abdullah M Alajlan; Writing - original draft, Bilal Rah and Abdullah Alnuqaydan; Writing - review \& editing, Bilal Rah, Abdulmajeed G Almutary, and Abdullah Alnuqaydan. All the authors have read and agreed to the published version of the manuscript.

\section{Compliance with ethical standards}

Conflicts of Interest The authors declare there is no conflict of interest.

\section{References}

1. Roodman GD (2004) Mechanisms of bone metastasis. N Engl J Med 350:1655-1664 
2. Tang DG, Porter AT (1997) Target to apoptosis: a hopeful weapon for prostate cancer. Prostate 32:284-293

3. Valastyan S, Weinberg RA (2011) Tumor metastasis: molecular insights and evolving paradigms. Cell 147:275-292

4. Baudino A T (2015) Targeted cancer therapy: the next generation of cancer treatment. Curr Drug Discov Technol 12:3-20

5. Mehlen P, Puisieux A (2006) Metastasis: a question of life or death. Nature reviews cancer 6:449458

6. Stavridi F, Karapanagiotou EM, Syrigos KN (2010) Targeted therapeutic approaches for hormonerefractory prostate cancer. Cancer treatment reviews 36:122-130

7. Suardi N, Gallina A, Lista $\mathrm{G}$ et al (2014) Impact of adjuvant radiation therapy on urinary continence recovery after radical prostatectomy. European urology 65:546-551

8. Zhang J, Cunningham JJ, Brown JS, Gatenby RA (2017) Integrating evolutionary dynamics into treatment of metastatic castrate-resistant prostate cancer. Nature communications 8:1-9

9. Hilal L, Shahait M, Mukherji D et al (2015) Prostate cancer in the Arab world: A view from the inside. Clin Genitourin Cancer 13:505-511

10. Arafa MA, Rabah DM (2017) With increasing trends of prostate cancer in the Saudi Arabia and Arab World: Should we start screening programs? World J Clin Oncol 8:447

11. Al-Abdin OZ, Al-Beeshi IZ (2018) Prostate cancer in the Arab population: an overview. Saudi Med J 39:453

12. Ito K (2014) Prostate cancer in Asian men. Nature Reviews Urology 11:197

13. Kaur R, Kapoor K, Kaur H (2011) Plants as a source of anticancer agents. J Nat Prod Plant Resour 1:119-124

14. Verma N, Shukla S (2015) Impact of various factors responsible for fluctuation in plant secondary metabolites. Journal of Applied Research on Medicinal Aromatic Plants 2:105-113

15. Alnuqaydan AM, Rah B (2019) Tamarix articulata (T. articulata)-an important halophytic medicinal plant with potential pharmacological properties. Curr Pharm Biotechnol 20:285-292

16. Said S, Noureddine G, Eddine LS et al (2018) Phenolic content, HPLC analysis and antioxidant activity extract from Tamarix gallica and Tamarix articulata growing in Southeast of Algeria. Research journal of pharmacy technology 11:3826-3832

17. Shaalan YM, Handoussa $H$, Youness RA et al (2018) Destabilizing the interplay between miR-1275 and IGF2BPs by Tamarix articulata and quercetin in hepatocellular carcinoma. Nat Prod Res $32: 2217-2220$

18. Alnuqaydan AM, Rah B (2020) Comparative assessment of biological activities of different parts of halophytic plant Tamarix articulata (T. articulata) growing in Saudi Arabia. Saudi Journal of Biological Sciences 27:2586-2592 
19. Arbiser JL, Kau T, Konar M et al (2007) Solenopsin, the alkaloidal component of the fire ant (Solenopsis invicta), is a naturally occurring inhibitor of phosphatidylinositol-3-kinase signaling and angiogenesis. Blood 109:560-565

20. Hou S, Cheng Z, Wang W et al (2018) Ailanthone exerts an antitumor function on the development of human lung cancer by upregulating microRNA-195. Journal of cellular biochemistry 120:1044410451

21. Du J, Daniels DH, Asbury C et al (2006) Mitochondrial production of reactive oxygen species mediate dicumarol-induced cytotoxicity in cancer cells. J Biol Chem 281:37416-37426

22. Kampa-Schittenhelm KM, Salitzky O, Akmut F et al (2016) Dronabinol has preferential antileukemic activity in acute lymphoblastic and myeloid leukemia with lymphoid differentiation patterns. BMC Cancer 16:1-12

23. Dai $Z$, Wang $L$, Wang $X$ et al (2018) Oxymatrine induces cell cycle arrest and apoptosis and suppresses the invasion of human glioblastoma cells through the EGFR/PI3K/Akt/mTOR signaling pathway and STAT3. Oncol Rep 40:867-876

24. Li Y, Yao J, Han C et al (2016) Quercetin, Inflammation and Immunity. Nutrients 8:167. https://doi.org/10.3390/nu8030167

25. Frazzi R, Valli R, Tamagnini I et al (2013) Resveratrol-mediated apoptosis of hodgkin lymphoma cells involves SIRT1 inhibition and FOXO3a hyperacetylation. International journal of cancer 132:10131021

26. Huang T-H, Lin C-F, Alalaiwe A et al (2019) Apoptotic or antiproliferative activity of natural products against keratinocytes for the treatment of psoriasis. Int J Mol Sci 20:2558

27. Rah B, Amin H, Yousuf $K$ et al (2012) A novel MMP-2 inhibitor 3-azidowithaferin A (3-azidoWA) abrogates cancer cell invasion and angiogenesis by modulating extracellular Par-4. PloS one 7:e44039

28. Sinha S, Mishra P, Amin H et al (2013) A new cytotoxic quinolone alkaloid and a pentacyclic steroidal glycoside from the stem bark of Crataeva nurvala: Study of anti-proliferative and apoptosis inducing property. Eur J Med Chem 60:490-496

29. Zilla MK, Nayak D, Amin H et al (2014) 4'-Demethyl-deoxypodophyllotoxin glucoside isolated from Podophyllum hexandrum exhibits potential anticancer activities by altering Chk-2 signaling pathway in MCF-7 breast cancer cells. Chemico-Biol Interact 224:100-107

30. Rasool RU, Nayak D, Chakraborty S et al (2017) AKT is indispensable for coordinating Par-4/JNK cross talk in p21 downmodulation during ER stress. Oncogenesis 6:e341-e341

31. Sreelatha S, Jeyachitra A, Padma PR (2011) Antiproliferation and induction of apoptosis by Moringa oleifera leaf extract on human cancer cells. Food Chem Toxicol 49:1270-1275

32. Kaur M, Velmurugan B, Rajamanickam S et al (2009) Gallic acid, an active constituent of grape seed extract, exhibits anti-proliferative, pro-apoptotic and anti-tumorigenic effects against prostate carcinoma xenograft growth in nude mice. Pharmaceutical research 26:2133-2140 
33. Björklund M, Koivunen E (2005) Gelatinase-mediated migration and invasion of cancer cells. Biochimica et Biophysica Acta (BBA)-Reviews on Cancer 1755:37-69

34. Kumar S, Weaver VM (2009) Mechanics, malignancy, and metastasis: the force journey of a tumor cell. Cancer Metastasis Rev 28:113-127

35. Hwang HJ, Park HJ, Chung H-J et al (2006) Inhibitory effects of caffeic acid phenethyl ester on cancer cell metastasis mediated by the down-regulation of matrix metalloproteinase expression in human HT1080 fibrosarcoma cells. J Nutr Biochem 17:356-362

36. Dinicola S, Pasqualato A, Cucina A et al (2014) Grape seed extract suppresses MDA-MB231 breast cancer cell migration and invasion. Eur J Nutr 53:421-431

37. Sarker D, Reid AH, Yap TA, De Bono JS (2009) Targeting the PI3K/AKT pathway for the treatment of prostate cancer. Clin Cancer Res 15:4799-4805

38. Shukla S, MacLennan GT, Hartman DJ et al (2007) Activation of PI3K-Akt signaling pathway promotes prostate cancer cell invasion. International journal of cancer 121:1424-1432

39. ur Rasool R, Rah B, Amin H et al (2016) Corrigendum: Dual modulation of Ras-Mnk and PI3K-AKTmTOR pathways: A Novel c-FLIP inhibitory mechanism of 3-AWA mediated translational attenuation through dephosphorylation of elF4E. Scientific reports 6

40. Katsuno Y, Lamouille S, Derynck R (2013) TGF- $\beta$ signaling and epithelial-mesenchymal transition in cancer progression. Current opinion in oncology 25:76-84

41. Bencherif K, Boutekrabt A, Fontaine J et al (2015) Impact of soil salinity on arbuscular mycorrhizal fungi biodiversity and microflora biomass associated with Tamarix articulata Vahll rhizosphere in arid and semi-arid Algerian areas. Sci Total Environ 533:488-494

42. Hebi M, Farid O, Ajebli M, Eddouks M (2017) Potent antihyperglycemic and hypoglycemic effect of Tamarix articulata Vahl. in normal and streptozotocin-induced diabetic rats. Biomedicine pharmacotherapy 87:230-239

43. Hebi M, Hajji L, Eddouks M (2018) Effect of flavonoid-rich extract of Tamarix articulata Vahl. on glucose and lipid metabolism in normal and diabetic rats. Cardiovascular \& Hematological Agents in Medicinal Chemistry. (Formerly Current Medicinal Chemistry-Cardiovascular \& Hematological Agents) 16:94-105

44. Cassady JM, Baird WM, Chang C-J (1990) Natural products as a source of potential cancer chemotherapeutic and chemopreventive agents. Journal of natural products 53:23-41

45. Patridge E, Gareiss P, Kinch MS, Hoyer D (2016) An analysis of FDA-approved drugs: natural products and their derivatives. Drug discovery today 21:204-207

46. Buranrat B, Noiwetch S, Suksar T, Ta-Ut A (2020) Inhibition of cell proliferation and migration by Oroxylum indicum extracts on breast cancer cells via Rac1 modulation. Journal of pharmaceutical analysis 10:187-193

47. Parr C, Ali AY (2018) Boswellia frereana suppresses HGF-mediated breast cancer cell invasion and migration through inhibition of c-Met signalling. Journal of translational medicine 16:1-12 
48. Stetler-Stevenson WG, Aznavoorian S, Liotta LA (1993) Tumor cell interactions with the extracellular matrix during invasion and metastasis. Annu Rev Cell Biol 9:541-573

49. Altomare DA, Testa JR (2005) Perturbations of the AKT signaling pathway in human cancer. Oncogene 24:7455-7464

50. Saji M, Ringel MD (2010) The PI3K-Akt-mTOR pathway in initiation and progression of thyroid tumors. Molecular cellular endocrinology 321:20-28

51. Singh I, Amin H, Rah B, Goswami A (2013) Targeting EGFR and IGF 1R: a promising combination therapy for metastatic cancer. Front Biosci (Schol Ed) 5:231-246

52. Vara JÁF, Casado E, de Castro J et al (2004) PI3K/Akt signalling pathway and cancer. Cancer treatment reviews 30:193-204

53. Margadant $C$, Sonnenberg A (2010) Integrin-TGF- $\beta$ crosstalk in fibrosis, cancer and wound healing. EMBO Rep 11:97-105

54. Zhang L, Cheng X, Gao Y et al (2016) Curcumin inhibits metastasis in human papillary thyroid carcinoma BCPAP cells via down-regulation of the TGF- $\beta / S m a d 2 / 3$ signaling pathway. Experimental cell research 341:157-165

55. Kou B, Liu W, Zhao W et al (2017) Thymoquinone inhibits epithelial-mesenchymal transition in prostate cancer cells by negatively regulating the TGF- $\beta /$ Smad $2 / 3$ signaling pathway. Oncol Rep 38:3592-3598

\section{Figures}




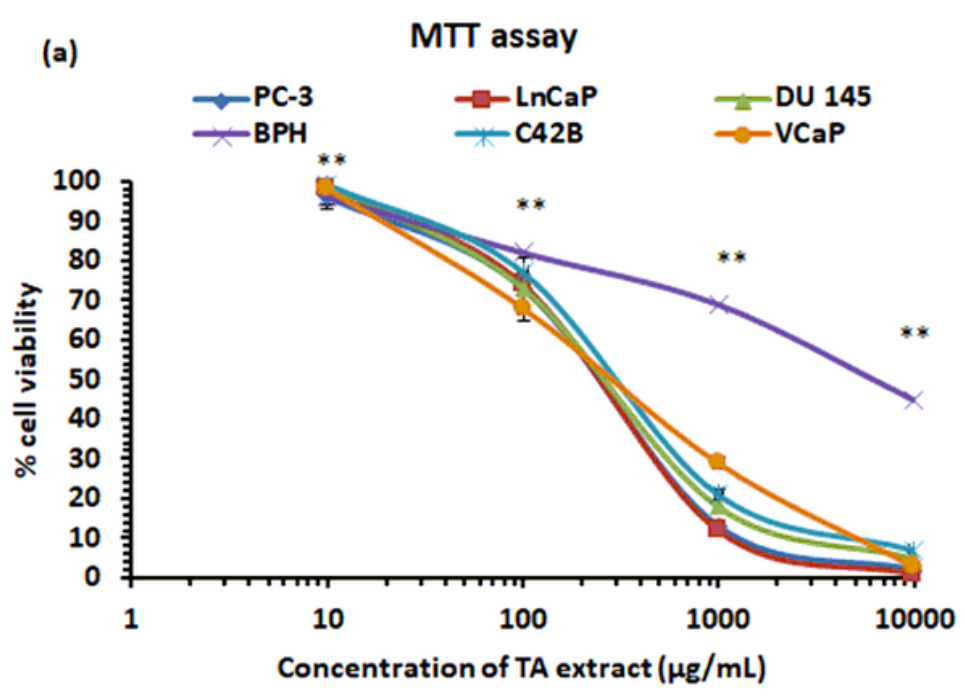

(b) (c)

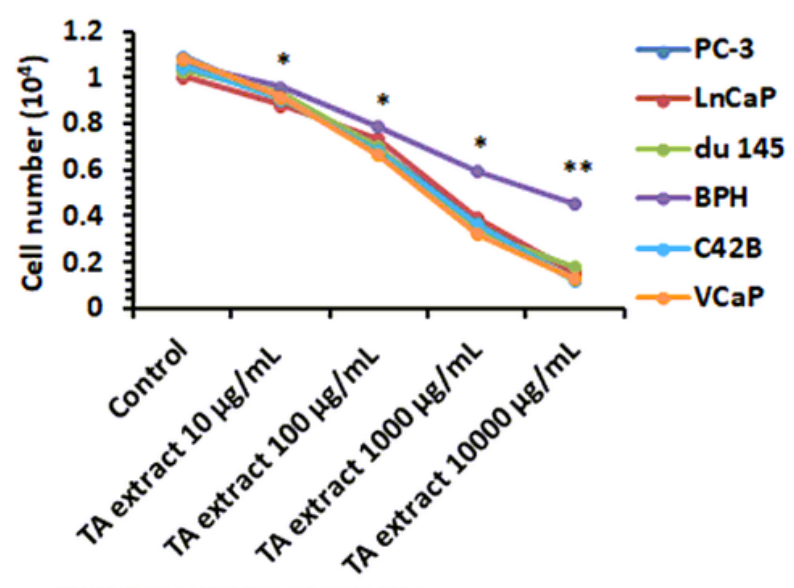

(d)
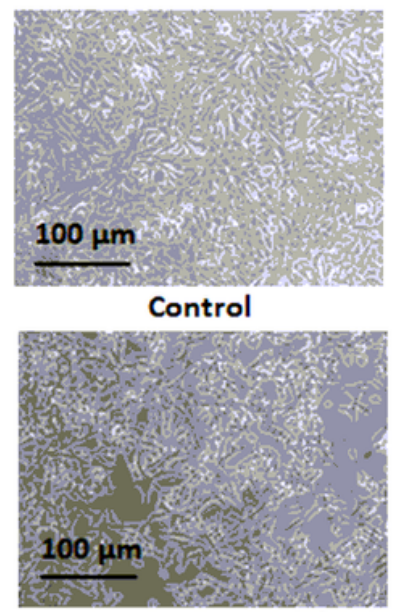

TA extract $67.5 \mu \mathrm{g} / \mathrm{mL}$

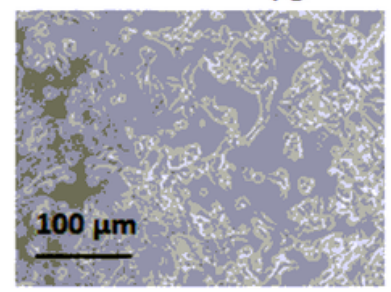

TA extract $250 \mu \mathrm{g} / \mathrm{mL}$

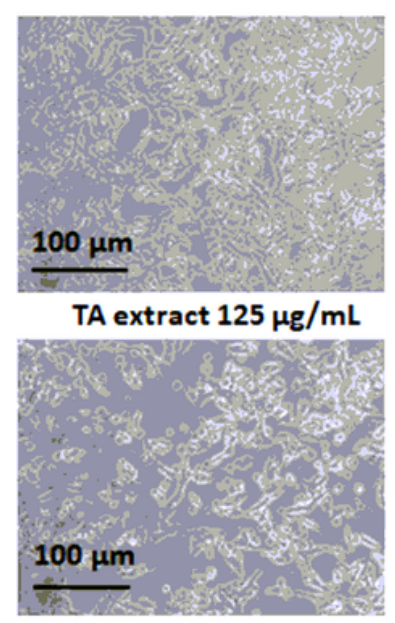

TA extract $500 \mu \mathrm{g} / \mathrm{mL}$

Figure 1

TA extract inhibits cell proliferation of prostate cancer cells. a MTT assay showed a dose-dependent inhibition of prostate cancer cell panel (PC-3, LnCaP, DU 145, C42B, and VCaP) and normal transformed prostate cells $(\mathrm{BPH})$ upon treatment with varying doses $(1,10,100,1000,10000 \mu \mathrm{g} / \mathrm{mL})$ of TA extract for $24 \mathrm{~h}$. b Brd U incorporation assay to determine cell proliferation of prostate cancer cells after exposed to different doses of TA extract for $24 \mathrm{~h}$. c Trypan blue exclusion assay to determine the cell viability of prostate cancer cells after varying treatments of TA extract for $24 \mathrm{~h}$. d Phase-contrast microscopy to analyze changes in cellular morphology of prostate cancer cells ( $\mathrm{LnCaP}$ ) after treatment with different doses of TA extract $(67.5,125,250,500 \mu \mathrm{g} / \mathrm{mL})$ for $24 \mathrm{~h}$. The representation of data is the mean value of $\pm S E$ of three or more than three independent experiments with statistical significance equal to ${ }^{*}<0.05$, $\star \star \mathrm{p}<0.01$. 


\section{(a)}

TUNEL
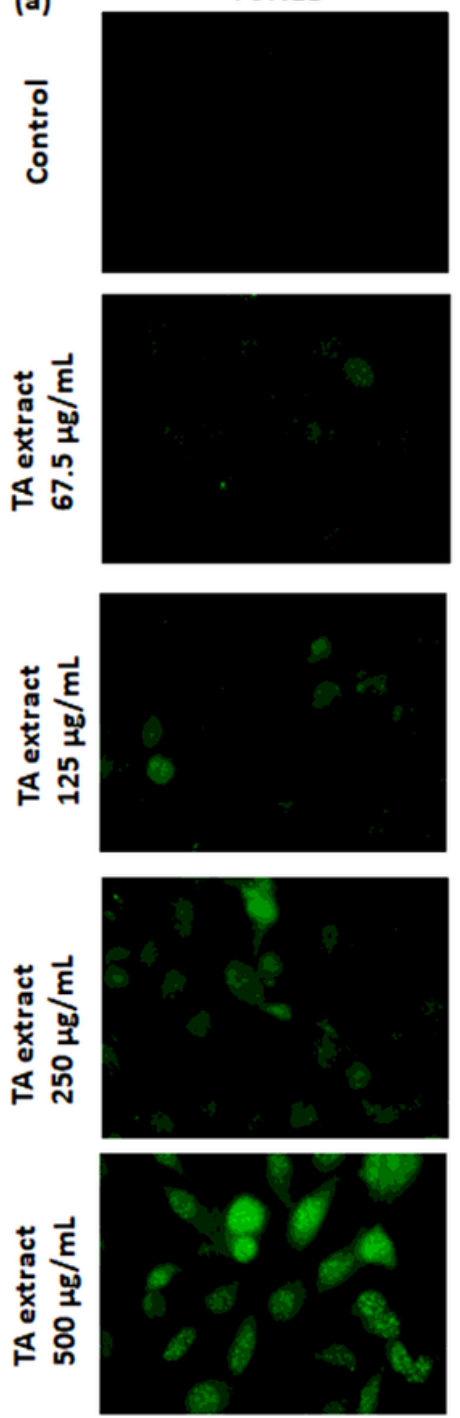

DAPI
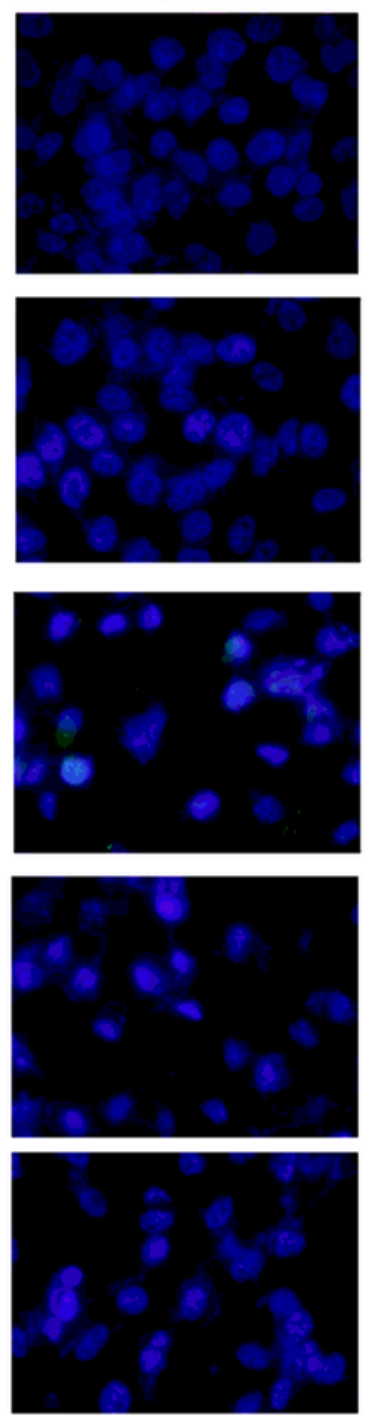

MERGE
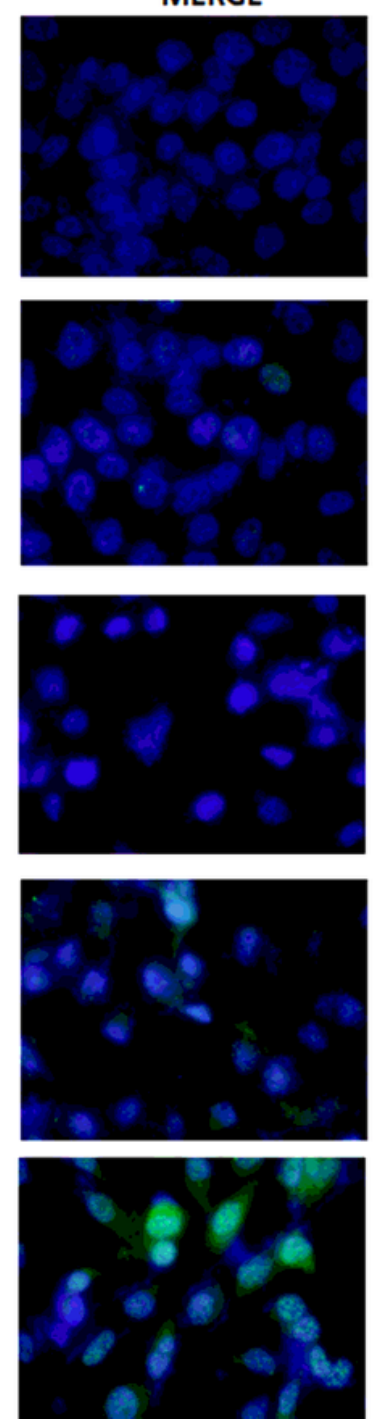

(b)

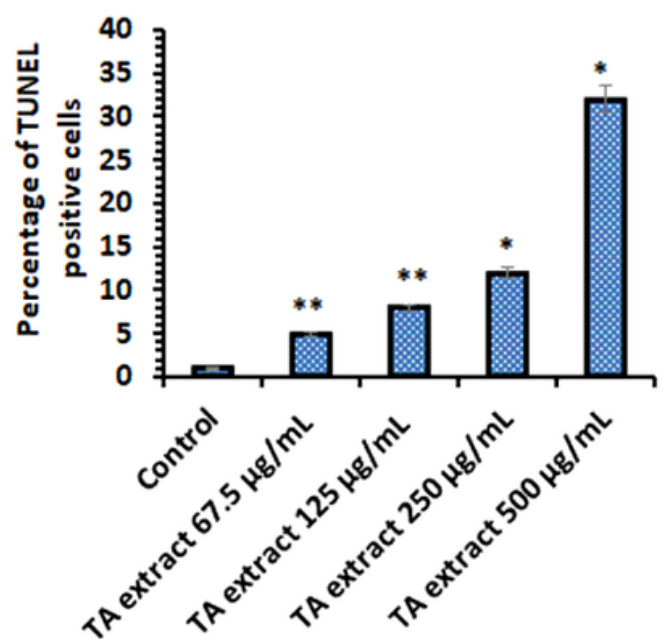

Figure 2

TA extract promotes apoptotic mode of cell death in prostate cancer (LnCaP) cells. a Visualization of TUNEL assay staining of apoptotic LnCaP cells after exposure to varying doses of TA extract $(67.5,125$, 250, $500 \mu \mathrm{g} / \mathrm{mL}$ ) for $24 \mathrm{~h}$. b Histogram represents the percentage of TUNEL-positive cells after exposed to varying doses of TA extract $(67.5,125,250,500 \mu \mathrm{g} / \mathrm{mL})$ for $24 \mathrm{~h}$. The representation of data is the mean value of $\pm S E$ of three or more than three independent experiments with statistical significance equal to ${ }^{*} p<0.05,{ }^{* \star} p<0.01$. 


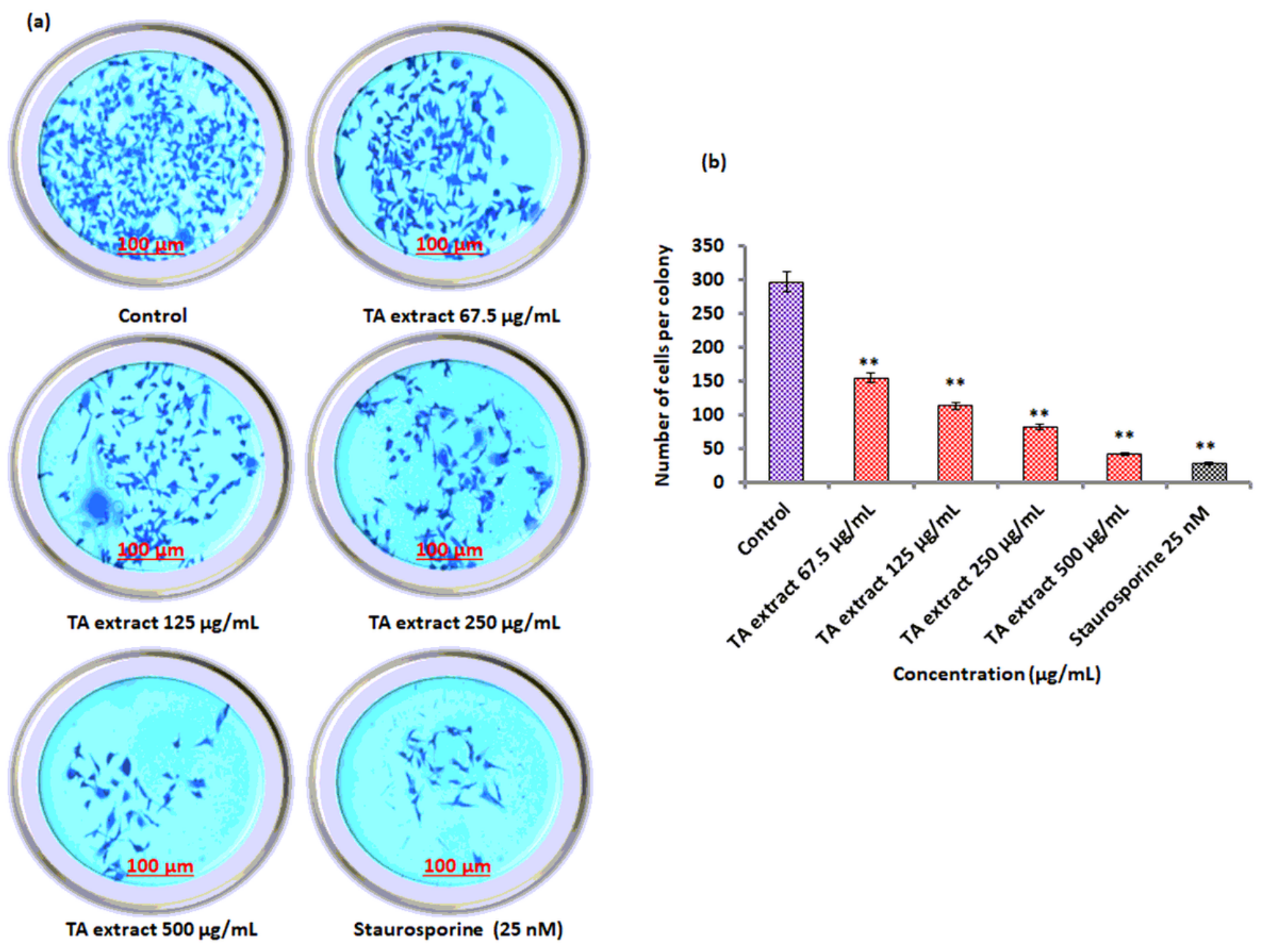

Figure 3

TA extract attenuates the clonogenic property of prostate cancer cells. a Represents the treatment of prostate cancer cells ( $\mathrm{LnCaP}$ ) with varying doses of TA extract along with untreated control and positive control staurosporine for $24 \mathrm{~h}$ to evaluate the anti-colony formation activity of TA extract. The scale bar is $100 \mu \mathrm{m}$ with $10 \mathrm{x}$ magnification. $\mathrm{b}$ The bar diagram represents the quantification of prostate cancer (LnCaP) cells per colony per field following treatment with varying doses of TA extract $(67.5,125,250$, $500 \mu \mathrm{g} / \mathrm{mL}$ ) for $24 \mathrm{~h}$. The representation of data is the mean value of $\pm S E$ of three or more than three independent experiments with statistical significance equal to ${ }^{*} \mathrm{p}<0.01$. 
(a)
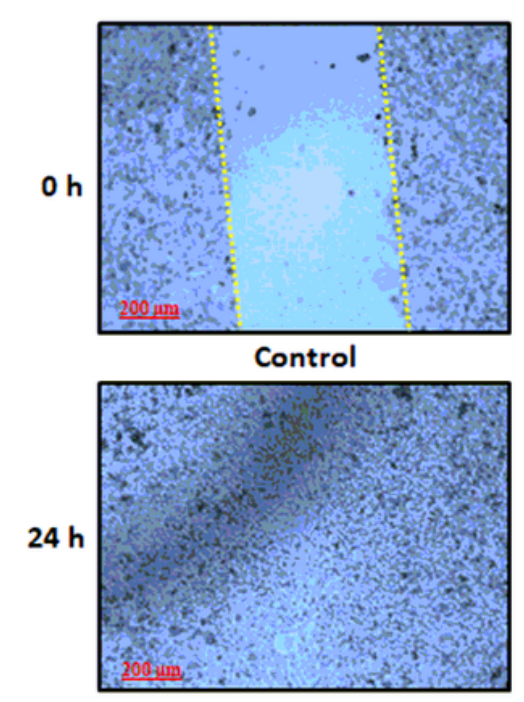

Control

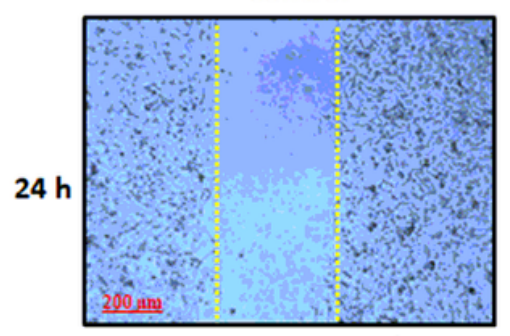

TA extract $250 \mu \mathrm{g} / \mathrm{mL}$

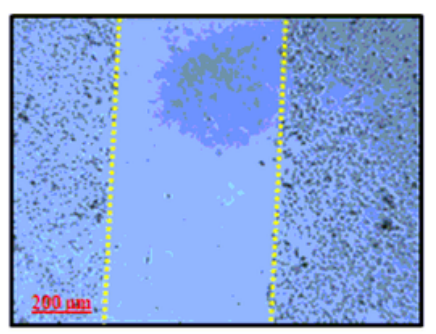

Camptothecin $(2 \mu \mathrm{M})$

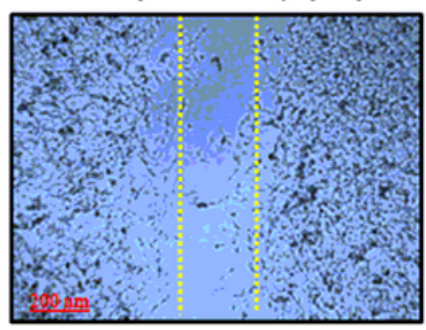

TA extract $125 \mu \mathrm{g} / \mathrm{mL}$ (b)
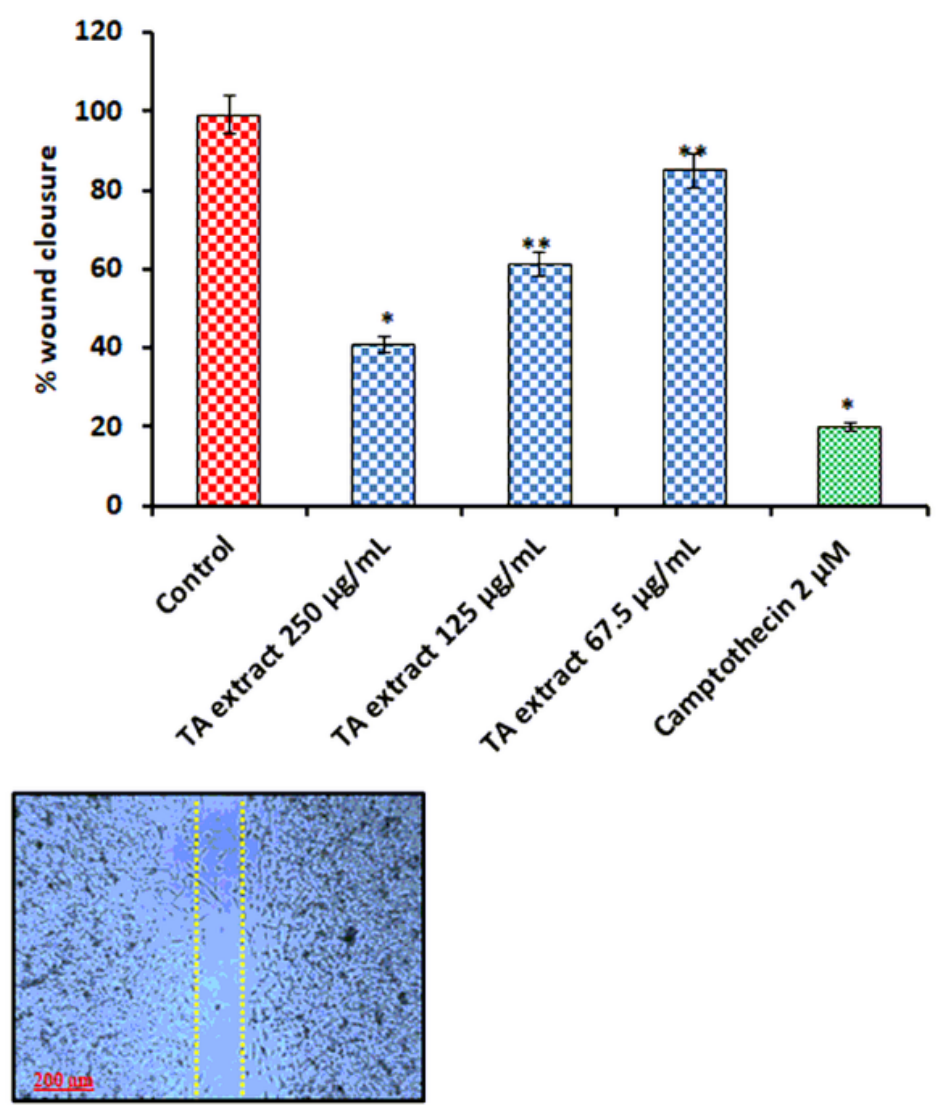

TA extract $67.5 \mu \mathrm{g} / \mathrm{mL}$

\section{Figure 4}

TA extract abrogates cell migration of prostate cancer cells. a Prostate cancer cells ( $\mathrm{LnCaP}$ ) were exposed to indicate concentrations of TA extract $(67.5,125$, and $250 \mu \mathrm{g} / \mathrm{mL})$ along with untreated control and positive control camptothecin $(2 \mu \mathrm{M})$ for $24 \mathrm{~h}$ to determine the motility of cells. The scale bar is 100 $\mu \mathrm{m}$ with 10x magnification. $\mathrm{b}$ The bar diagram represents the percentage of wound closure of prostate cancer (LnCaP) cells in control and in wells treated with varying doses of TA extract $(67.5,125,250,500$ $\mu \mathrm{g} / \mathrm{mL}$ ) for $24 \mathrm{~h}$. The representation of data is the mean value of \pm SE of three or more than three independent experiments with statistical significance equal to $* * p<0.01$. 


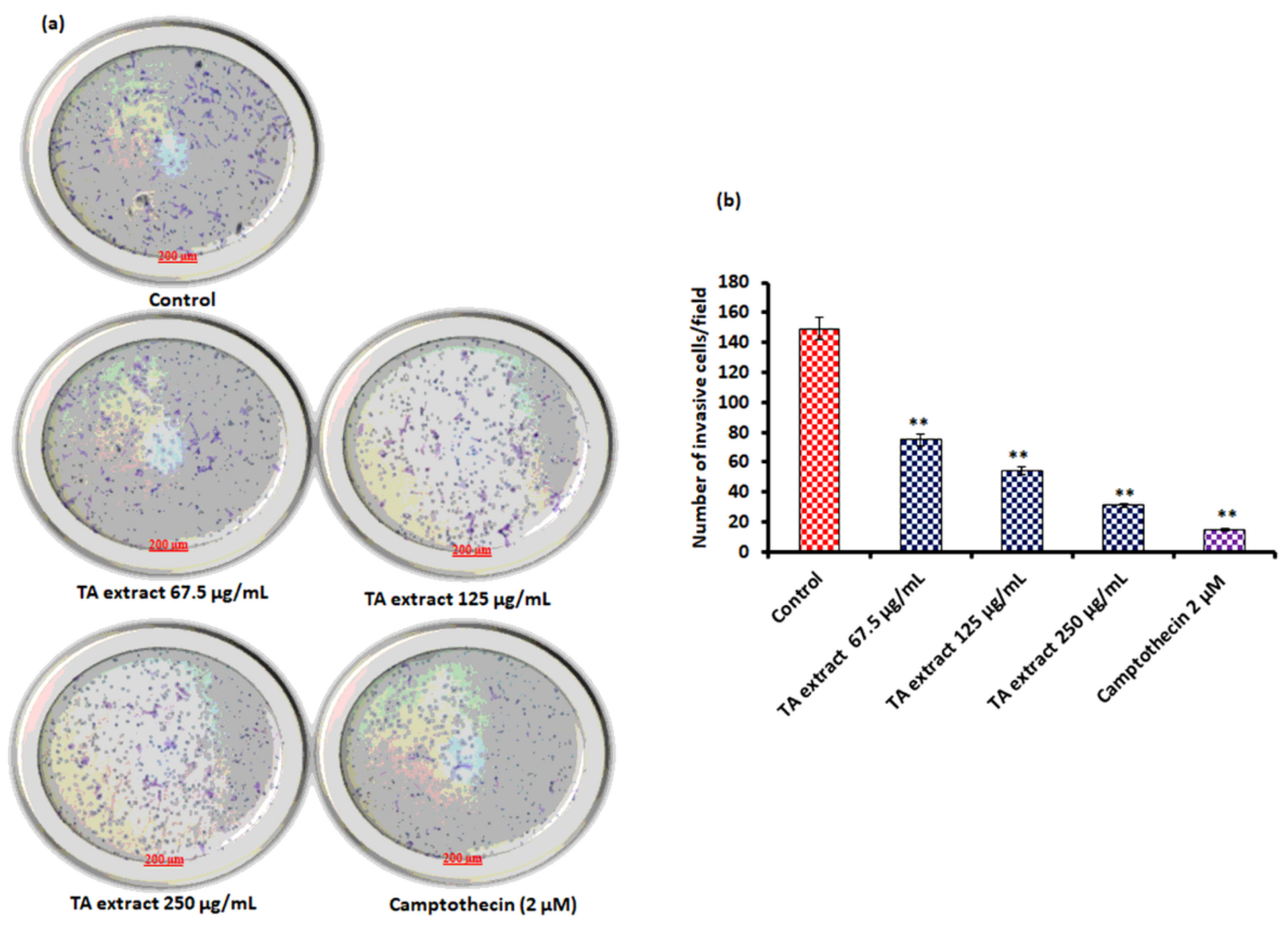

Figure 5

TA extract inhibits cell invasion property of prostate cancer (LnCaP) cells. a LnCaP $2 \times 105$ cells were seeded in the upper insert of Transwell Boyden chamber and simultaneously indicated doses of TA extract $(67.5,125,250,500 \mu \mathrm{g} / \mathrm{mL})$ were added along with untreated control and positive control camptothecin $(2 \mu \mathrm{M})$ for $24 \mathrm{~h}$ to evaluate the anti-invasive potential of TA extract. The scale bar is 100 $\mu \mathrm{m}$ with 10x magnification. $\mathrm{b}$ The bar diagram represents the number of invaded prostate cancer (LnCaP) cells across the porous Matrigel membrane in control and in upper inserts treated with varying doses of TA extract $(67.5,125,250,500 \mu \mathrm{g} / \mathrm{mL})$ for $24 \mathrm{~h}$. The representation of data is the mean value of $\pm S E$ of three or more than three independent experiments with statistical significance equal to ${ }^{*} p<0.01$. 
(a)

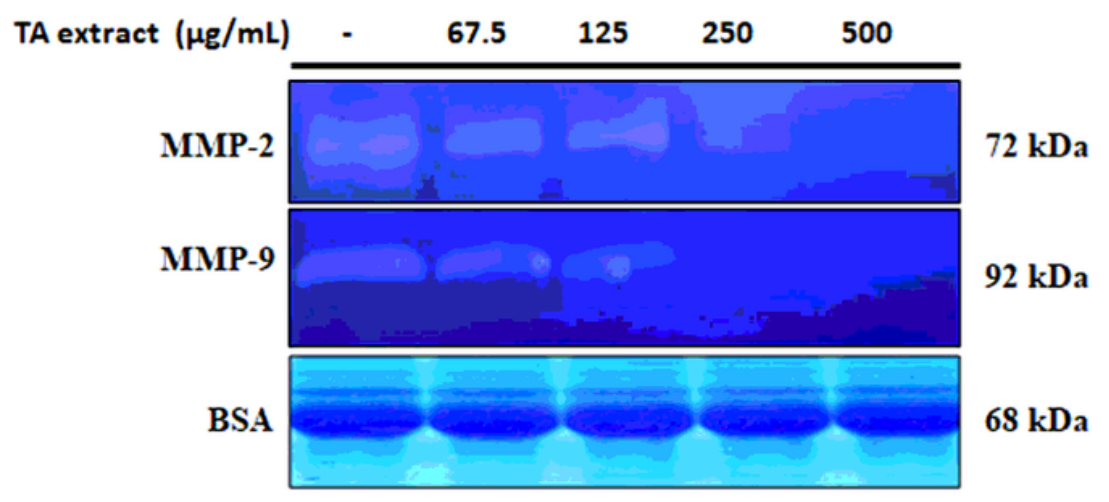

(c)

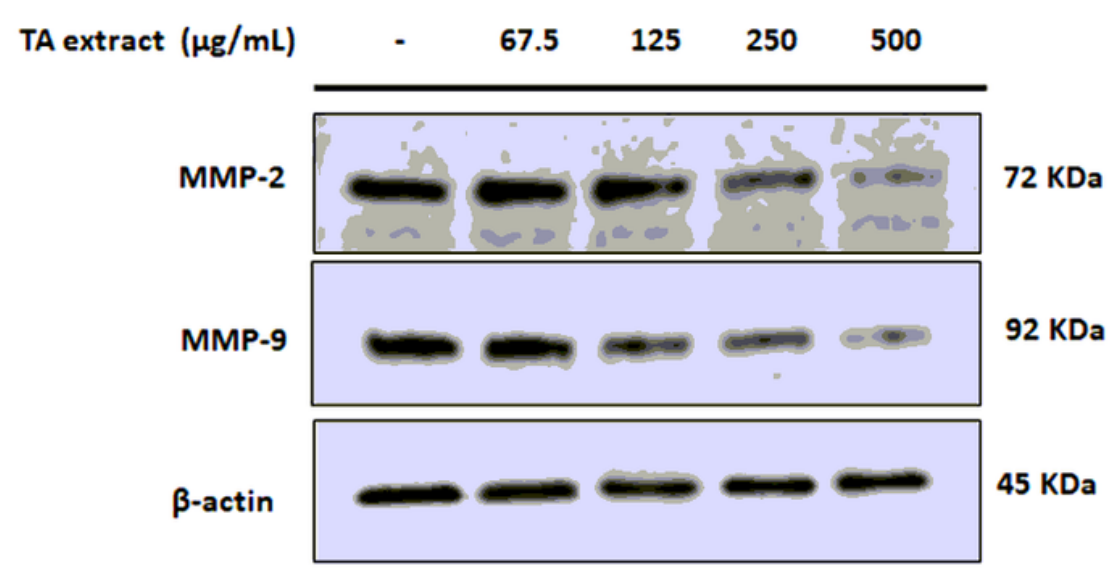

(b)

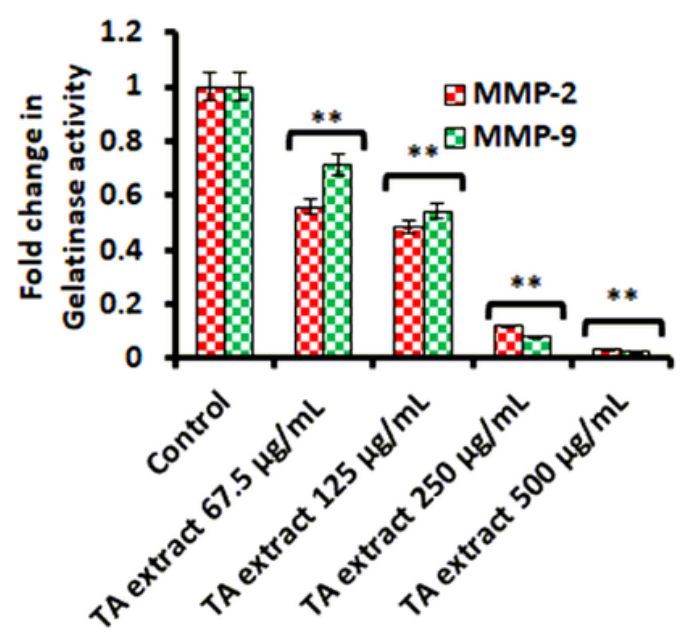

(d)

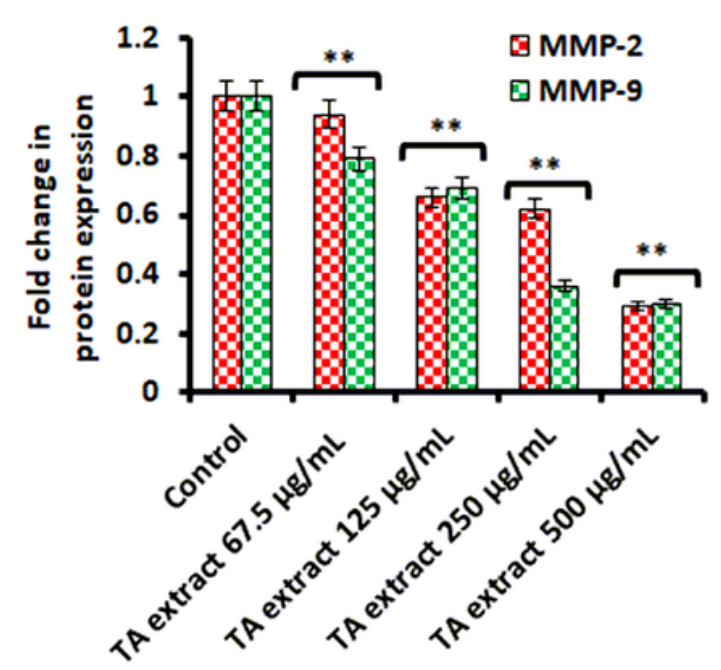

\section{Figure 6}

TA extract abrogates the matrix metalloproteinases (MMP-2/-9) activity and expression in prostate cancer (LnCaP) cells. a Represents the gelatinase activity of MMP-2, MMP-9, and loading control BSA in conditional media samples collected from separate wells of cells exposed to varying doses of TA extract along with untreated control for $24 \mathrm{~h}$. b The representative histograms show gelatinase activity (fold change) in conditional media samples exposed to varying doses of TA extract. c Protein expression of matrix metalloproteins (MMP-2/-9) and an internal loading control in conditional media samples exposed to indicate doses of TA extract along with untreated control for $24 \mathrm{~h}$. $\mathrm{d}$ Represents fold change in protein expression of MMP-2/-9 after being normalized with internal control $\beta$-action by densitometry analysis. The representation of data is the mean value of $\pm S E$ of three or more than three independent experiments with statistical significance equal to ${ }^{* *} p<0.01$. 
(a)

TA extract $(\mu \mathrm{g} / \mathrm{mL})$

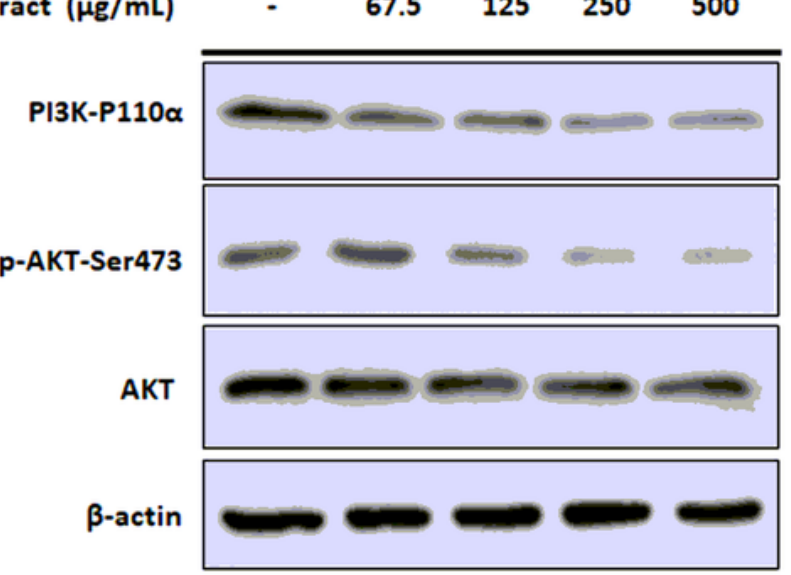

(c)

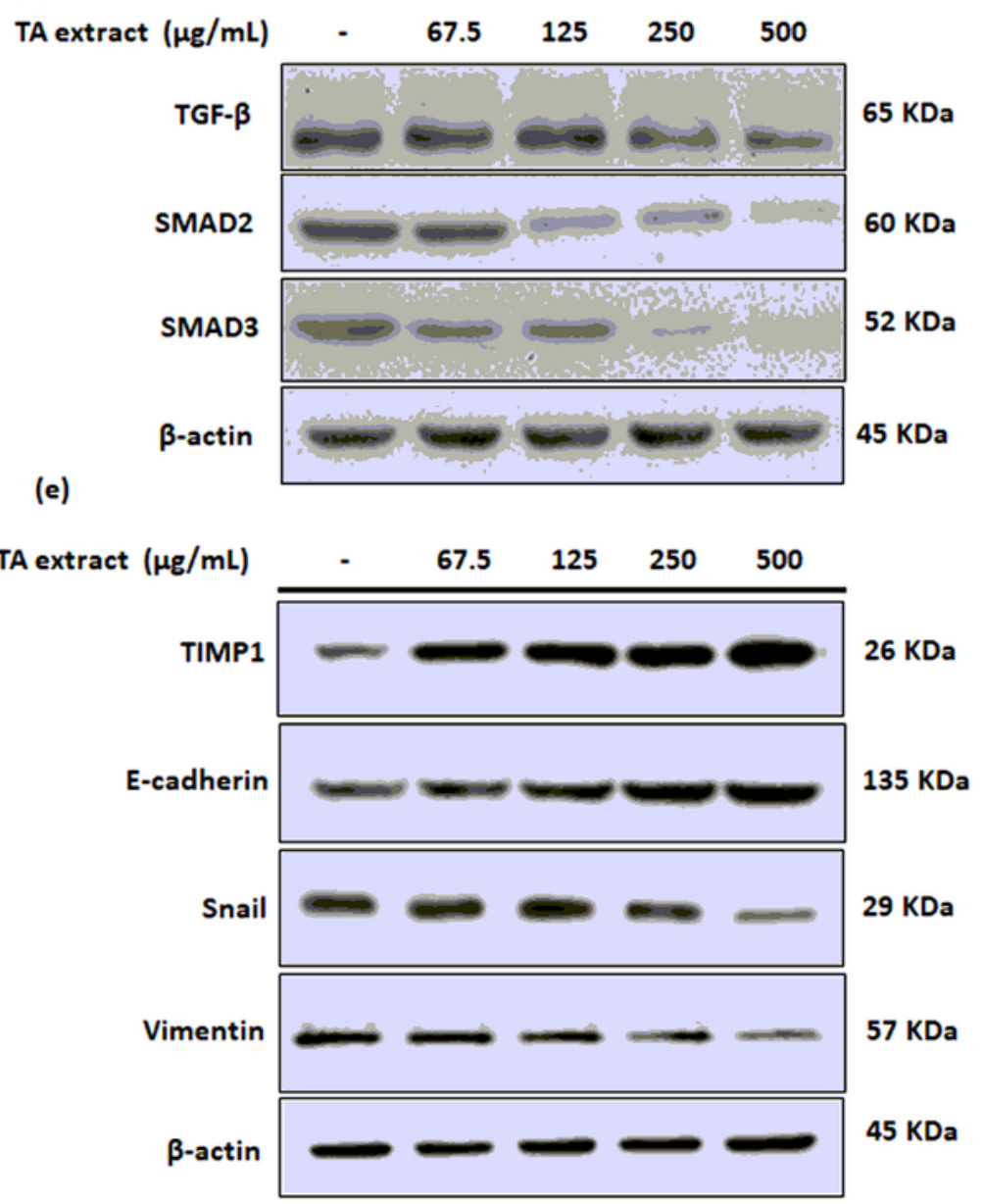

(b)

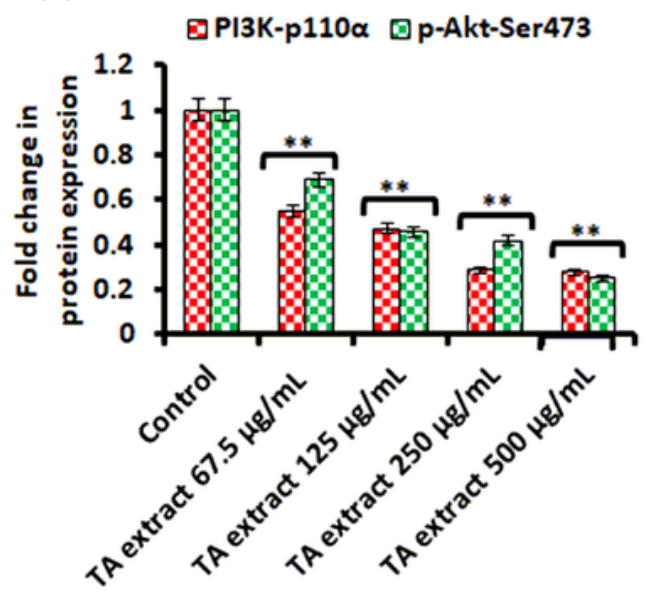

(d)
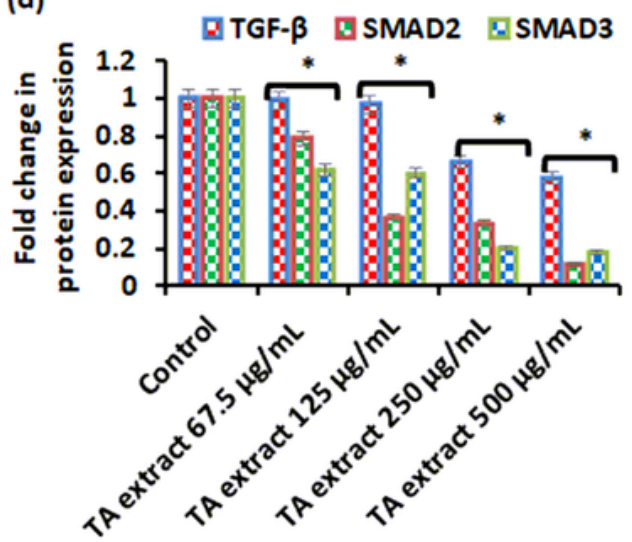

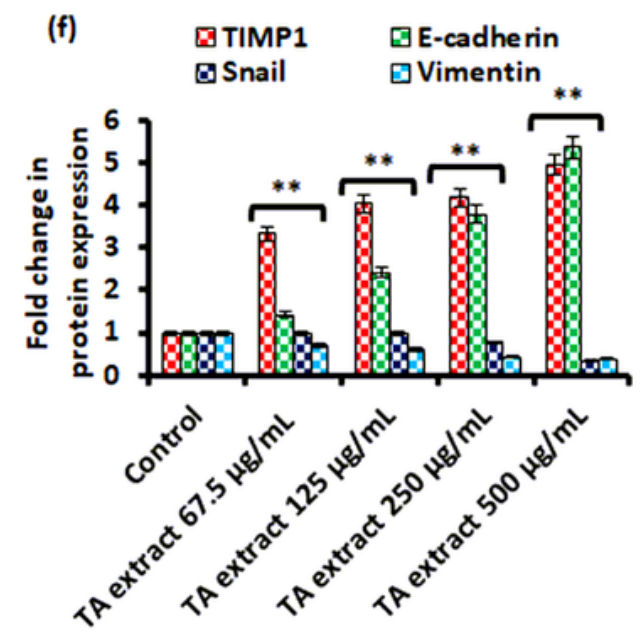

Figure 7

Modulation of PI3K/Akt signaling and its downstream targets by TA extract in prostate cancer cells. a Protein expression by Western blotting of prostate cancer ( $\mathrm{LnCaP}$ ) cells after treatment with varying doses of TA extract $(67.5,125$, and $250 \mu \mathrm{g} / \mathrm{mL})$, indicates the change in expression of PI3K-P110a, Akt, pAkt-Ser473 and an internal control $\beta$-action. b Represents fold change in protein expression of PI3KP110a, and p-Akt-Ser473 after being normalized with internal control $\beta$-action by densitometry analysis. c 
Protein expression by Western blotting of prostate cancer (LnCaP) cells after treatment with varying doses of TA extract $(67.5,125$, and $250 \mu \mathrm{g} / \mathrm{mL})$, indicates the change in expression of TGF- $\beta$, SMAD2, SMAD3 and an internal control $\beta$-action. $d$ Represents fold change in protein expression of TGF- $\beta$, SMAD2, SMAD3 after being normalized with an internal control $\beta$-action by densitometry analysis. $e$ Protein expression by Western blotting of prostate cancer cells ( $\mathrm{LnCaP})$ after treatment with varying doses of TA extract in the presence of untreated control indicates the change in expression of TIMP1, Ecadherin, snail, vimentin, and an internal control $\beta$-action. $f$ Represents fold change in protein expression of TIMP1, E-cadherin, snail, and vimentin, after being normalized with internal control $\beta$-action by densitometry analysis. The representation of data is the mean value of \pm SE of three or more than three independent experiments with statistical significance equal to ${ }^{*} p<0.05,{ }^{\star *} p<0.01$.

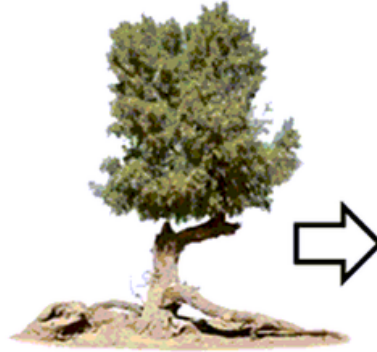

Tamarix articulata

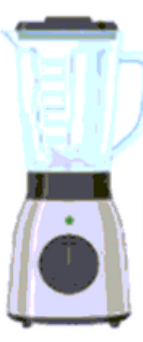

Blender

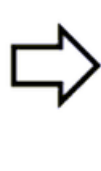

Dry powder

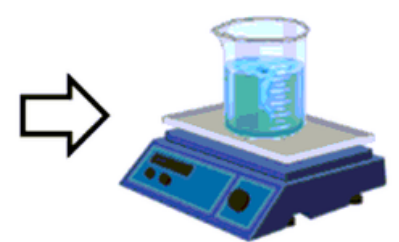

Dissolved in methanol and stirred for 5 days

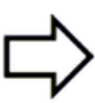

Filtered and air dried

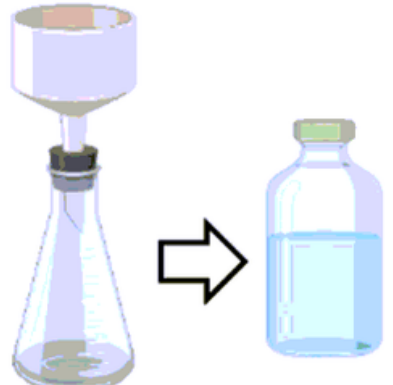

Methanolic extract Stock solution

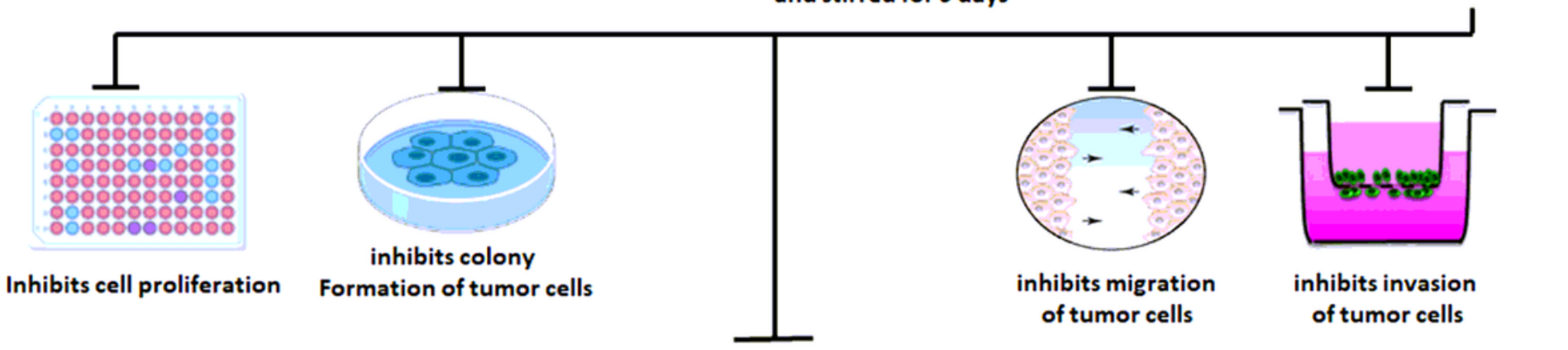

Mechanistically Tamarix articulata blocks PI3K/Akt signaling and mesenchymal epithelial transition (MET) of cells
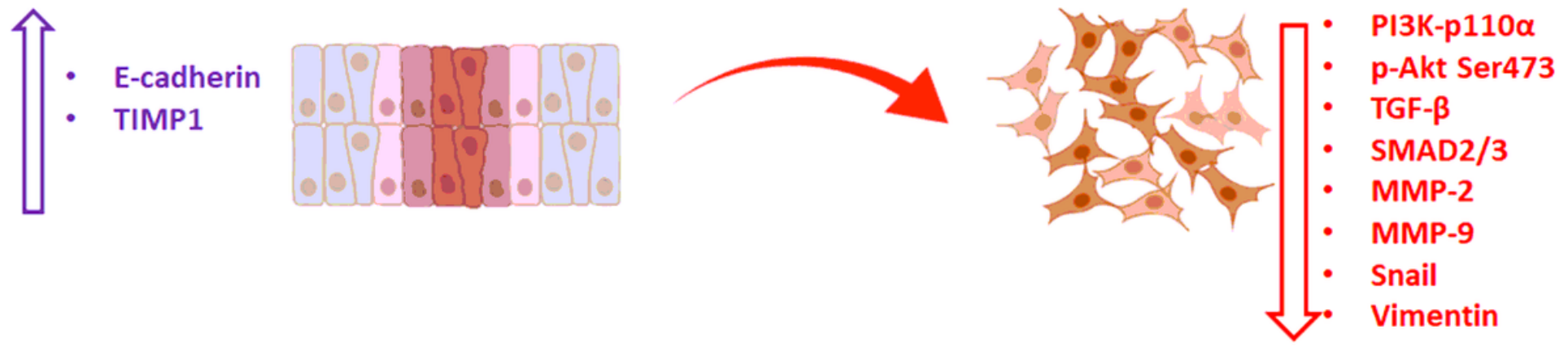

\section{Figure 8}

Schematic diagram showing the stages of methanolic extraction of TA and how it exerts antiproliferative, antimotility, anti-invasive effects, and possible antimetastatic mechanism against prostate (LnCaP) cancer cells. 


\section{Supplementary Files}

This is a list of supplementary files associated with this preprint. Click to download.

- SupplementaryFigure1 ofLCMSofTAextract.pdf

- SupplementaryTable1ofLCMSofTAextract.pdf 